\title{
Do Derivatives Matter?: Evidence From A Policy Experiment
}

\author{
Deepak Agrawal, K R Subramanyam, Prasanna Tantri and \\ Ramabhadran S Thirumalai*
}

December 13, 2015

\footnotetext{
*Agrawal may be reached at deepak_agrawal@isb.edu, Subramanyam at krs@marshall.usc.edu, Tantri at prasanna_tantri@isb.edu and Thirumalai at ram_thirumali@isb.edu. We would like to thank the NSE and NYU for financial support received through the NSE-NYU Stern Initiative on the Study of Indian Capital Markets. We are grateful to Viral Acharya, Pulak Ghosh and participants of the Finance Summer Research Camp 2015 at the Indian School of Business for helpful comments. We would also like to thank the NSE-ISB Trading Laboratory for providing the required data. Any remaining errors are ours alone.
} 


\title{
Do Derivatives Matter?: Evidence From A Policy Experiment
}

\begin{abstract}
We study the impact of derivatives on various stock characteristics such as valuation, price efficiency, and liquidity. We resolve the endogeneity issue faced in the extant literature by using an order issued by the Indian market regulator that resulted in the delisting of 51 stocks from the derivative segment. Using this policy experiment, we examine the conflicting hypothesis regarding the impact of derivatives on stock fundamentals. We find that excluded firms underperform the market by $4.07 \%$ during the event window. We identify a decline in price efficiency and reduction in liquidity as channels through which the above phenomenon manifests. Contrary to the expectations of the regulators, volatility remains largely unchanged. We rule out regulatory targeting by employing several placebo and robustness tests. We conclude that derivatives indeed add value by improving price efficiency and liquidity of a stock.
\end{abstract}




\section{Introduction}

Financial economists have recognized that a fuller understanding of the way an asset is priced requires a clear knowledge of the influence of derivative instruments, which use the asset under consideration as an underlying, on the fundamental characteristics of the asset (An et al. (2014), Johnson and So (2012), Easley et al. (1998)). However, despite their first order importance and extensive research for over four decades, there is widespread disagreement regarding the influence exercised by derivatives on fundamental characteristics of an asset such as valuation, price efficiency, liquidity, volatility, etc. A number of studies have found that derivatives have a positive impact on the underlying asset value by completing markets (Ross (1976)), enhancing informational efficiency of stock prices (Cao (1999), Easley et al. (1998), Roll et al. (2009), Naiker et al. (2012), Blanco and Wehrheim (2015)), improving liquidity (Berkman et al. (1998)) and reducing volatility (Damodaran and Lim (1991)). It has also been noted that derivatives alter the distribution of stock returns (Ni et al. (2005)). On the other hand, some studies (Danielsen and Sorescu (2001), Ho and Liu (1997)) find that derivatives depress stock prices as they reduce short sale constraints. Some others have shown that derivatives do not have much of an impact. For example, Muravyev et al. (2013) show that option prices do not convey additional information. Vijh (1990) shows that large option trades have no impact on stock prices and bid-ask spreads. Given the above conflicting findings, Ni et al. (2005) claim that "the literature relating to option introductions and expirations has not shown that equity option trading significantly impacts the prices of underlying stocks."

Such widespread disagreement regarding the impact of derivative securities stems from the lack of clear identification events to empirically examine the impact of derivatives. Researchers have used derivatives listing (Conrad (1989), Kumar et al. (1998), Danielsen and Sorescu (2001)), the volume of derivative trading (Johnson and So (2012), Roll et al. (2009, 2010), Admati and Pfleiderer (1988)) and lead-lag relationship between the spot and the derivative markets (Muravyev et al. (2013), Hu (2014)) to determine the impact of derivatives on stock characteristics. None of the above methods clearly identify the impact of derivatives as there are endogenous explanations for the observed impact. Derivatives listing has been shown to be endogenously decided by the exchange based on expected ex post outcomes that the researchers seek to orthogonolize and study. ${ }^{1}$ Other two methods also face

\footnotetext{
${ }^{1}$ Mayhew and Mihov $(2004,2005)$ show that the decision to list a stock in the options segment is endogenously determined by trading volume and volatility over the pre-listing period. In Mayhew and Mihov (2004), the control group consists of stocks that meet the minimum criteria for listing in the options market but were not listed by the exchanges. More importantly, their logit model, which predicts listing based on $e x$ ante characteristics, also predicts ex post outcomes attributed to derivative listing. Therefore, it is difficult
} 
similar identification challenges. As these studies themselves point out, stocks with high options volume may be very different when compared to those with low option volume in many unobservable ways and the option volume may just reflect those differences in characteristics. Similar arguments may be made for the lead-lag based studies as well. Not surprisingly, therefore, the results of extant studies on the impact of derivatives have significantly varied based on the asset class studied (Das et al. (2014)), the time period of the study (Detemple and Jorion (1990)), the context of the study as reflected by the occurrence of major events (Cao (1999)), the nature of the derivative contract (Berkman et al. (1998)), and many other observable and unobservable factors.

We overcome the above identification problems by examining a regulatory order issued by the Securities Exchange Board of India ${ }^{2}$ (SEBI) due to which 51 stocks were delisted from the derivative segment. On July 23, 2012, SEBI tightened the criteria for a stock to continue to trade in the derivative segment. Derivative listing criteria in India are based on thresholds, which depend on insider ownership and liquidity over the prior six months. The intent of the regulator was to allow derivative trading in stocks that are widely held and are highly liquid. The thresholds for continuation in the derivative segment were increased by SEBI. We believe that the event was completely devoid of any endogenous factors for the following reasons. First, the old as well as new thresholds were based on historical as well as publicly available information, whose impact, if any, is likely to have been priced in (Kaul et al. (2000)). Second, in order to test if there is regulatory targeting as pointed out by (Karlan and Zinman (2010)), we plot the levels of the variables on which the exit decision is based for a period of six months before the SEBI order. In Figure 1, we plot the values of the variables ${ }^{3}$ on which exclusion decision is on based for excluded stocks ove the six-month period prior to exclusion. As can be seen, the measures for excluded stocks are relatively stable in the six months prior to exclusion. Further, there is no dramatic decrease in these measures just prior to SEBI changing the criteria for continued listing. Therefore, it is reasonable to conclude that the exclusion is a result of an increase in the thresholds rather than any change in excluded stock characteristics. Third, it is well known that insider ownership tends to be sticky (Kaserer and Moldenhauer (2008)). Therefore, in order to rule out any residual concerns regarding regulatory targeting, we also study the price reaction of only those stocks that get excluded only because of failure to meet the revised insider

to deny the possibility that stocks may be listed in the options market based on expected real outcomes. Danielsen et al. (2007) show that derivative listing is accompanied by market-wide changes, which have an impact on stock characteristics. Thus, the documented post listing impact of options could be an artifact of the selection criteria for listing.

${ }^{2}$ The Indian security market regulator

${ }^{3}$ We describe the variables in detail in Section 3 
ownership threshold. ${ }^{4}$. Fourth, and more importantly, unlike the situations considered by the extant literature (Mayhew and Mihov (2004, 2005)), the stock exchanges do not select the stocks to be listed or delisted. Compliance with SEBI regulations is mandatory for all stock exchanges. Therefore, endogenous selection by stock exchanges with an eye on future business opportunities is less of a concern in our setting. ${ }^{5}$ Finally, we perform several placebo tests to confirm the robustness of our results.

We first examine the impact of derivatives on stock returns in the short run around the announcement of the list of stocks to be excluded. From the above discussion, three contradictory hypothesis emerge. First, Conrad (1989) and others show that derivatives add value positively. Under the above hypothesis, an exogenous derivative delisting is likely to lead to negative permanent price reaction. Second, Danielsen and Sorescu (2001) show that derivatives exert downward pressure on stock prices due to easing of short-sale constraints. Under the above hypothesis, derivative delisting is likely to lead to a positive price reaction as short selling constraints increase post delisting. Finally, classical theories (Black and Scholes (1973)) consider derivatives as passive securities, in which case derivative delisting should not result in any significant price reaction.

We find that the stocks delisted from the derivative segment under-perform the broader market by $2.82 \%$ during our event window, which spans from 5 days before to 5 days after the event date. ${ }^{6}$ Further, the negative returns are not recouped even six months after the exclusion announcement. In order to understand the complete impact of derivatives, we create an event window by combining days around both the announcement of the exclusion as well as the actual exclusion. ${ }^{7}$ Using the expanded window, we find that the excluded stocks under-perform the broader market by $4.07 \%$. The significant negative reaction to derivative exclusion clearly indicates that derivatives indeed add value to a stock. We then examine the impact of exclusion on total trading turnover of a stock using an event study framework. We find that stock turnover declines by between $29.1 \%$ to $54.8 \%$ around derivative exclusion.

Having established a link between derivatives and stock valuation, we then move on to establish the channels through which this link works. We start by investigating the link between derivatives and price efficiency. The extant literature has produced conflicting

\footnotetext{
${ }^{4}$ In other words, these stocks are well above the required thresholds for the other two criteria

${ }^{5}$ In fact, newspaper reports indicate that the exchanges opposed SEBI's decision to increase the thresholds, which resulted in fewer derivatives being listed.

${ }^{6}$ The above result is robust to change in the event window.

${ }^{7}$ Existing derivatives on the excluded stocks were allowed to expire as per schedule. In India, derivatives trade on a three-month cycle. At any given time, there are near-month, next-month, and far-month contracts available. On SEBI's announcement date, July 2012, August 2012, and September 2012 contracts were trading. The actual exclusion date is the expiration date of the September 2012 contracts.
} 
findings in this regard. While some important studies (Hu (2014), Easley et al. (1998)) have shown that derivatives play an important role in price discovery, others (Chan et al. (2002), Muravyev et al. (2013), Vijh (1990)) show that this is not true. Given the nature of the event, our setting allows us to cleanly measure the impact of derivatives on the informational efficiency of stocks.

We use the price efficiency measures in Hou and Moskowitz (2005). The broad idea underlying the measures is the following: if prices are efficient, then market-wide events are likely to be priced quickly. In such a scenario, after controlling for the impact of contemporaneous market returns, lagged market returns are not expected to explain current stock returns in a significant way. In case they do, then it is a sign of inefficiency. We find that the ability of lagged market returns to explain stock returns of the excluded stocks increases by between $5.2 \%$ to $7.3 \%$. We estimate the price efficiency regressions using a difference-in-difference framework and following Das et al. (2014) we use, in separate tests, both a pooled control sample as well a matched control sample. In order to gauge the magnitude of change in price efficiency, we use a second measure (called D2) from Hou and Moskowitz (2005). This measure is simply the ratio between the coefficient on lagged market returns upon the sum of the coefficients on contemporaneous market returns and lagged returns. We find that the relative value of loadings on lagged market returns increase when compared to the loadings on the contemporaneous market returns. The economic magnitude of such increase ranges between $7.1 \%$ to $9.6 \%$. From the above mentioned results, it is clear that price efficiency decreases after derivative exclusion.

To further buttress our findings, we examine the number of analysts following the treatment and control firms before and after derivative exclusion. Roll et al. (2009) show that stocks with higher options activity also attract higher analyst following, which in turn increases the informational efficiency of a stock. We find that the number of analysts following the treatment firms significantly declines after delisting. The result holds even when we implement difference-in-difference specification using firms that continue to be listed as control group. These results show that the informational efficiency of the prices declines post delisting from the derivative segments. In other words, derivatives significantly contribute towards information production by inviting trades of informed outside investors.

The second channel that we examine is change in liquidity. Kumar et al. (1998) show that options help in enhancing the liquidity of a stock. It is also well known that arbitrageurs, market makers, and noise traders operate both in spot as well as derivatives markets to take advantage of any arbitrage opportunities, to hedge positions, or for reasons which at best can be termed as noise $(\mathrm{Hu}(2014))$, respectively. Derivative delisting may drive away 
many such players who trade in both markets and thereby reduce liquidity in the equity market. We test for change in trading volume in the equity market of affected stocks. We find that the stock turnover in the spot market declines significantly post delisting. We test the impact of derivatives on liquidity using a battery of measures used in (Das et al. (2014)). These measures range from simple daily volume to more comprehensive measures such as the Roll impact measure and Amihud's illiquidity measure. All twelve measures of liquidity that we examine show a significant decline in liquidity in the post derivative delisting period. An overall permanent decrease in liquidity for the treatment stocks results in lower valuation (Amihud and Mendelson (1986)). These results indicate that derivatives contribute significantly towards stock liquidity as well.

We then test the impact of derivatives on stock volatility. As per classical theories, under full diversification idiosyncratic risks do not matter. However, recent studies have shown that due to under-diversification idiosyncratic risks do matter for stock valuations (Fu (2009)). Using a difference-in-difference framework, we test the impact of derivatives on stock volatility. We use the measures used in Das et al. (2014). We do not detect any change in volatility post delisting. However, skewness and kurtosis of returns show a significant increase.

Finally, we perform a number of tests to establish the robustness of our results. First, we test for parallel trends (Bertrand et al. (2002a)) and find them in all our difference-in -difference tests. Second, we conduct the following placebo tests to rule out alternative explanations. We repeat all our event studies and regression-based tests using several false announcement and implementation dates. In these tests, we keep the exclusion criteria unaltered. We do not find any effects when we conduct tests based on false dates. If our results are driven by the fact that excluded firms had low outsider shareholding or low trading volume prior to delisting and not because of delisting, one would expect to get results similar to our main results even in our placebo tests. We also conduct a false limit test where we define our treatment group based on false limits without changing the event date. Here again, we do not find any difference between the treatment and control groups.

This paper contributes to the literature on the impact of derivatives on the underlying stock by showing that derivatives positively impact stock valuation. The paper also contributes to the literature on informativeness of stock prices by showing that information efficiency is higher in the presence of derivatives than in their absence. We also show that derivatives indeed improve liquidity and hence contribute positively to stock valuations. Further, unlike existing inferences that are predominantly based on options, our inferences are not just limited to options but can be extended to futures as well. The Indian derivative 
market comprises of both options as well as futures, with both categories trading actively. Finally, and most importantly, this paper exploits a regulatory event that is devoid of any endogenous information and to that extent produces clean identification, lack of which has been a major challenge for the extant literature in delineating the impact of derivatives.

The rest of the paper proceeds as follows. Section 2 provides institutional background. Section 3 describes the event. Section 4 describes the data and summary statistics. Section 5 describes our empirical strategy and results. Section 6 concludes.

\section{Background}

In this section, we describe the relevant institutional background.

\subsection{Brief History}

Stock trading in India has a history of more than 140 years. ${ }^{8}$ The Bombay Stock Exchange(BSE), which is the oldest stock exchange in Asia, was established in the year 1875. In 1956, the Government of India, after passing the Securities Contract Regulation Act, recognized the BSE as a stock exchange. India's first broad-based market index the "Sensex" 9 was introduced in 1986. Another large stock exchange, the National Stock Exchange of India (NSE), was established in 1992 by domestic as well as foreign financial institutions. It soon became the largest stock exchange in India and is currently the 12th largest in the world in terms of market capitalization of listed firms and fourth largest in the world in terms of the annual number of trades in equities. ${ }^{10}$ Over $99 \%$ of all stock trading in India is through these two exchanges.

\subsection{Current State}

India has a highly liquid stock market. Average daily volume of trading in India is to the extent of INR 3 trillion (approximately USD 50 billion). ${ }^{11}$ A World Bank report ${ }^{12}$ shows that between 2010 and 2012, Indian stock market turnover to GDP ratio stood at 45.3\%, which is higher than many developed markets such as France, Germany, and Italy, and almost all

\footnotetext{
${ }^{8}$ Source: http://www.bseindia.com/static/about/heritage.aspx?expandable $=0$

${ }^{9}$ Sensex comprises of 30 large companies in India from different sectors of the economy

${ }^{10}$ NSE's market index is known as the CNX Nifty. It represents 50 large companies in India.

${ }^{11}$ Source: www.moneycontrol.com

${ }^{12}$ Source: http://data.worldbank.org/indicator/CM.MKT.TRAD.GD.ZS/countries
} 
emerging markets other than China. The fact that India is now the fastest growing large economy in the world ${ }^{13}$ has attracted both domestic as well as foreign institutional capital to Indian markets. Net investment by Foreign Institutional Investors exceeded INR 1 trillion (USD 16.5 billion) in 2014. These facts indicate that India has a well-functioning stock market with robust governance and regulatory mechanisms in place.

\subsection{Derivatives In India}

Equity derivatives were introduced in India in the year 2000. Unlike the U.S. (Mayhew and Mihov (2004)), India started with index futures and options and introduced stock futures and options in the following year. ${ }^{14}$ Very soon, the derivative segment became bigger than the underlying equity segment. At the beginning of the year 2015, derivative transactions accounted for nearly $91 \%$ of all transaction volume in the stock exchanges. ${ }^{15}$ One important reason for the relative popularity of derivatives is the lower taxes in that segment. As noted in the literature (Diamond and Verrecchia (1987), Danielsen and Sorescu (2001)), derivatives ease short-sale constraints. Given that the short-sale constraints are severe in Indian spot markets (Berkman et al. (1998)), derivatives are relatively more attractive compared to other segments. Roll et al. (2009) note that in order for derivatives to have any impact, volume of trading is more important than the mere listing of derivatives. Given the high proportion of trading in derivatives, India offers an excellent setting to study the impact of derivative securities. Another important feature of Indian markets is that both options and futures are actively traded in India. Approximately $30 \%$ of derivative trading in India is in options and remaining in futures. This allows us to study the impact of both options as well as futures rather than options alone as is the case with the extant literature.

\subsection{Regulation}

SEBI was formed on April 12, $1992^{16}$ with the objective of protecting the interests of investors in securities and to promote the development of and to regulate the securities market and for matters connected therewith or incidental thereto. All kinds of stock derivative products fall under the regulatory purview of SEBI. SEBI, over the years, has earned a reputation of being a responsive and vigilant regulator. The fact that institutional failures in India such

\footnotetext{
${ }^{13}$ Source: IMF, World Bank

${ }^{14}$ Source: www.nseindia.com

${ }^{15}$ Source: www.nseindia.com, www.bseindia.com

${ }^{16}$ It was formed in accordance with the provisions of the Securities and Exchange Board of India Act, 1992.
} 
as broker failures have been few and far between after 2001 shows the efficacy of SEBI's regulations. ${ }^{17}$

\section{The Event}

Given that derivatives are complex instruments and come with high levels of leverage, regulators world over tend to be highly suspicious about them. In the U.S., the SEC took more than seven years to give permanent status to derivative exchanges (Mayhew and Mihov (2004)). Initially, the options exchange was given only "experimental status" The SEC declared a "voluntary moratorium" on options trading in 1979 to study the impact of options trading and design appropriate regulatory mechanisms. The SEC gave permanent status to options exchanges only in 1980.

SEBI has also been extremely cautious when it comes to derivatives. In fact, a forward trading facility known as the Badla (Berkman et al. (1998)) was blamed by SEBI for "excessive speculation" and volatility in the 1990s and was duly banned. Indian policy makers, in general, are apprehensive of derivative instruments and regularly call for imposition of restrictions on derivative trading, blaming derivative products for many negative consequences. For example, during periods of inflation, regulators conveniently ban forward trading in agricultural commodities ${ }^{18}$ although there is no credible evidence to suggest that derivative products lead to higher commodity prices (Sahoo and Kumar (2009), Bose (2007)). Keeping up with the same spirit and tradition, SEBI, in 2012, came to a conclusion that it is desirable to restrict trading in derivatives in order to protect "market integrity".

\subsection{The Criteria}

On July 23, 2012, SEBI issued guidelines tightening the qualification criteria for continued listing in the derivative segment. One of the criteria is dependent on the amount of outside ownership and other two were liquidity measures. Table 1 provides details about thresholds before and after the change in criteria. The criteria are defined as follows:

a. Market Wide Position Limit(MWPL): This measure is based on the floating stock of a company. The MWPL is defined as $20 \%$ of the number of shares held by non-promoters in the relevant underlying security. ${ }^{19}$ As shown in row 1 of Table 1 , the applicable limit

\footnotetext{
${ }^{17}$ Source: The Economic Times

${ }^{18}$ Details about one such instance are given in www.legalserviceindia.com

${ }^{19}$ Source: NSE
} 
of average MWPL over the prior six months was increased from INR 600 million to INR 2,000 million.

b. Median Quarter Sigma Order Size (MQSOS): It is the order size required to move the bid-ask midpoint by one fourth of the historical standard deviation of the stock returns, calculated over the prior six months. NSE calculates these numbers and makes them available publicly on a regular basis. As shown in row 2 of Table 1, the applicable limit for MQSOS was revised from INR 0.2 million to INR 0.5 million.

c. Minimum Monthly Turnover (MMT): It is the average monthly derivative turnover over the prior three months. SEBI introduced this new criterion, which was set at INR 1,000 million.

\section{Table 1 about here}

\subsection{The Reasons For Exclusion}

Stocks that failed to meet any one of the above criteria were excluded from the derivative segment. Stock exchanges were not given any discretion in this regard. However, contracts that existed as on July 23, 2012 (July 2012, August 2012 and September 2012 contracts) continued to trade until their respective expiration dates. Table 2 reports the number of stocks that were excluded after the change in criteria. 30 stocks were excluded solely because of breaching the new MWPL threshold, which is dependent on the amount of insider ownership.

\section{Table 2 about here}

\subsection{Possibility of Regulatory Targetting}

In order to test if there is regulatory targeting as pointed out by (Karlan and Zinman (2010)), we plot the levels of the variables on which the exclusion decision is based for a period of six months before the SEBI order in figure 1. As can be seen, MWPL, MMT and MQSOS for excluded stocks are relatively stable in the six months prior to exclusion. Further, there is no dramatic decrease in these measures just prior to SEBI changing the criteria. Therefore, it is reasonable to conclude that the exclusion is a result of increase in threshold (grey lines below) rather than any change in excluded stock characteristics.

Figure 1 about here 


\section{Data and Summary Statistics}

In this section, we briefly describe our data sources and relevant summary statistics.

\subsection{Data}

We obtain the data for our paper from following four sources;

a. NSE Web site: We obtain the list of firms excluded due the change in criteria from the NSE Web site. We also obtain historical data on MWPL, MQSOS, and MMT as well as derivative segment trading volume from the NSE Web site.

b. Center For Monitoring Indian Economy (CMIE) Prowess: We get price, volume, market capitalization, and turnover data from the Prowess database, maintained by CMIE. ${ }^{20}$ We also obtain some company-level financial information ,like sales, total assets, and price-to-book ratio from Prowess.

c. SEBI Web Site: We obtain all relevant SEBI circulars from their web site. From these circulars, we obtain information about derivative listing and delisting norms. We also learn about the effective dates of various regulations from this source.

d. Bloomberg: We obtain data regarding the number of analysts covering each stock from Bloomberg data base. We collect this data at a quarterly frequency.

\subsection{Summary Statistics}

We report summary statistics in Table 3 .

\section{Table 3 about here}

Columns 2,3 and 4, report the numbers for the set of firms that were excluded from the derivative segment and columns 5,6 and 7 report summary statistics for firms that continued in the derivative segment. In column 8 (9), we test for difference in mean (median). All values are given in millions of rupees and the reported values are from latest available

\footnotetext{
${ }^{20}$ Prowess has gained reputation as the Indian Compustat. The database provides detailed accounting and financial information for more than 25,000 large and medium companies in India. A number of prominent research articles (Khanna and Palepu (2000), Bertrand et al. (2002b), Gopalan et al. (2007), Vig (2013)) use the same database.
} 
financial statements as of July 23, 2012. From the table, it is clear that firms that are excluded are systematically smaller than continuing firms. For example, mean (median) values for assets for excluded firms is INR 2,853.9 (713.0) million whereas the same for firms that continued in the derivative segment is $\operatorname{INR} 7,441.4(2,860.0)$ million. Similar differences exist with respect to annual gross revenue and market capitalization. Both mean and median differences are statistically significant at the $99 \%$ level of confidence. In the next three rows, we report mean (median) values for exclusion criteria and also compare the mean (median) differences between excluded and continuing firms. Here again, continuing firms are systematically larger with respect to all three parameters. We next examine differences in valuation and profitability. There is no significant difference in the price-to-book ratio between the two groups. The mean (median) profit-to-sales ratio for the excluded stocks is $0.28(0.20)$, which is significantly lower than the mean (median) profit-to-sales ratio of 0.42 (0.27) for the continuing firms. Finally, we compare the two group of stocks with respect to trading volume. Here, we find that the trading volume both in cash market as well as derivative market is higher for continuing firms when compared to excluded stocks. ${ }^{21}$

\section{$5 \quad$ Empirical Strategy And Results}

In this section, we describe our empirical strategy.

\section{$5.1 \quad$ Impact on Valuation}

As we note in the introduction, a number of articles (Conrad (1989), Damodaran and Lim (1991), Danielsen and Sorescu (2001) have tested if derivatives improve or worsen stock valuation. We also note that the identification strategy used in the above studies is seriously questioned by subsequent articles (Mayhew and Mihov (2004), Danielsen et al. (2007)), which show that the results of earlier studies were influenced by the endogenous listing decision of exchanges. We revisit the question using an exogenous regulatory action as a setting to study the impact of derivatives on stock valuation.

\footnotetext{
${ }^{21}$ We perform similar comparisons by including stocks that get excluded solely because of MWPL in our treatment group and obtain similar results
} 


\subsubsection{Market Model}

We first estimate a market model to calculate the abnormal returns for the 50 stocks that were excluded from the derivative segment. We use the CNX200 Index as a proxy for the market. We calculate abnormal and cumulative abnormal returns using standard event windows used in the literature. T-statistics are computed following the procedure in Boehmer et al. (1991), which are adjusted for cross-correlation due to event-date clustering using the methodology described in Kolari and Pynnönen (2010). We estimate the results using both the announcement day of list of companies excluded from the derivatives segment as well as the actual day of exclusion as the event dates.

If derivatives have a salutary effect on stock value, then we expect:

a. negative abnormal returns around the date of announcement;

b. no reversal of returns after the event;

c. negative abnormal returns after actual delisting due to price pressure and hence could be temporary.

On the other hand, if derivatives are redundant, then we do not expect any abnormal returns around the event. Finally, if short-sale constraints dominate, then we expect a positive stock price reaction post delisting.

\subsection{Market Reaction}

The market reaction to exclusion of stocks from the derivative segment are in 2 and Tables $4 \mathrm{~A}$ and $4 \mathrm{~B}$. We report daily averages for five days before and five days after the event date. In table $4 \mathrm{~A}$, we consider the day after NSE announced the list of companies being excluded from the derivatives segment as the event day and in table $4 \mathrm{~B}$, we consider the actual exclusion date. SEBI issued the order on July 23, 2012 and following this the stock exchanges published the list of excluded stocks on July 24 at 5 P.M. Further, the updated data on MWPL, MQSOS, and MMT required for arriving at the list of excluded stocks was not available in the public domain on July 23 and hence the names of excluded stocks were revealed to the market participants only on July 24 and that too after market hours. Therefore, we consider July 25, 2012 as the event date (Day 0) for our event study examining market reaction to the announcement. With respect to actual exclusion, there is no such ambiguity. Derivative contracts in India expire on the last Thursday of a month and at any 
point of time, contracts are issued only for up to subsequent 2 months. Therefore, as on July 23, the SEBI notification date, derivative contracts for the months of July, August and September were available for trading. Therefore, the derivative trading on excluded stocks effectively ended on last Thursday of September 2012, which is September 27.

\section{Table $4 \mathrm{~A}$ and $4 \mathrm{~B}$ about here}

In table $4 \mathrm{~A}$, we report the event study results around the announcement date. The event time is measured as the number of trading days from the event date. $\mathrm{N}$ (in column 2) refers to number of treatment stocks. AR stands for abnormal return generated by the market model for a stock $i$ as on day $d$. CAR is the cumulative AR from day -5 to day d. Std CS test refers to t-statistics computed following the procedure in Boehmer et al. (1991). T-statistics are adjusted to take into account cross-correlation due to event-date clustering using the methodology described in Kolari and Pynnönen (2010). In column 3 (4), we report the mean (median) abnormal returns. In column 4 (5), we report the mean (median) cumulative abnormal returns. In column 5 (6), we report appropriate p-values for mean (median) CAR.

We find that stock reaction around the event is negative. The mean (median) CAR

over the -5 to +5 window is $-2.82 \%(-2.34 \%)$, both of which are economically as well as statistically significant.

We next plot CAR from 10 days before to 120 days after the event day in Figure 2. The idea is to see if the negative shock in Table $4 \mathrm{~A}$ reverses quickly or if it persists for a longer time. A persistent negative shock strengthens our inference that derivatives indeed add value rather than any temporary price pressure effects.

\section{Figure 2 about here}

CAR is negative even after 120 days after the event date. From the above, we infer that the negative price reaction due to derivative exclusion does not reverse immediately after the event and hence the reaction that we have documented is unlikely to be an instance of price pressure. We conduct further tests to test if the price reaction is permanent.

In order to gauge the market reaction to derivative exclusion in its entirety, it is important to look at the market reaction to the actual delisting as well. This is because any residual uncertainty with regards to implementation gets resolved on that day. We re-estimate the event study with the actual day of derivative exclusion as the event day and report the results 
in Table 4B. The cumulative abnormal return during our preferred -5 to +5 event window is statistically insignificant. However, there seems to be some temporary price pressure just before delisting as evidenced by the negative $1.89 \%$ cumulative abnormal return during the -5 to 0 window. However, unlike the announcement effect, this reverses itself within next 3 days.

\section{Table $4 \mathrm{C}$ about here}

Finally, in Table 4C, we combine the event studies reported in Table $4 \mathrm{~A}$ and Table $4 \mathrm{C}$ and report the cumulative market reaction over the -5 to +5 window after announcement and -5 to +1 window after actual exclusion. We restrict the post actual delisting period to just one day (instead of five days for announcement) after exclusion as information regarding exclusion was widely available. As can be seen in table $4 \mathrm{C}$, the mean (median) CAR from -5 to 46 day window ${ }^{22}$ is $-4.07 \%(-5.02 \%)$, which is both statistically as well as economically significant.

The results presented in Table 4C unambiguously show that derivative delisting leads to negative price reaction for excluded stocks. Given the exogenous nature of the event and the sharp price reaction that we detect using a narrow window around the announcement and exclusion dates, loss of value is indeed caused by derivative exclusion, or, in other words, derivatives add value to the stock. In the rest of the paper, we focus on establishing the robustness of the above result and also detecting the source of value added by derivative instruments.

\subsubsection{Robustness Tests}

We perform a number of tests to examine the robustness of our results. Before dwelling into the specifics of the robustness tests, it is important to note one possible source of endogeneity. It could be that these results reflect a reaction to a pre-existing trend in the variables used for determining derivative delisting. For example, if stocks that have declining liquidity are more likely to get excluded, then it is possible that such stocks experience negative returns (Amihud and Mendelson (1986)) once the market learns about such a decline. In this case, negative returns would ensue even without derivative delisting. A second related concern is related to regulatory targeting. Is it possible that regulators carefully chose the above limits based on some information not available publicly?

\footnotetext{
${ }^{22}$ Please note that we consider a total of 17 days, which consists of 11 days $(-5$ to +5$)$ around announcement and 6 days ( -5 to 1 ) around the actual event
} 
We note the following in this regard. First, as we pointed out in Figure 1, the three exclusion criteria (MWPL, MQSOS, and MMT) are based on publicly available historical information. The only new information is the revision in the criteria by SEBI. The revision is completely orthogonal to company fundamentals. As shown by Kaul et al. (2000), any price impact due to historical information should already be reflected in prices. For example, say, TVS Motors has a MQSOS of INR 0.3 million for the six months ending July 23, 2012 and due to SEBI's notification, the stock gets excluded. Then, it is unlikely that the MQSOS, which is public information, will move prices after the SEBI announcement. It is difficult to argue that impact of change in MWPL or MOSOS plays out after every six months.

Second, the argument that the results are a reaction to a pre-existing trend in MWPL, MQSOS, or MMT is likely to have merit only if there is a decreasing trend in those variables for the affected stocks and not for other stocks. Continuing with the TVS Motors example, say, in the last 10 days MWPL (or MQSOS or MMT) decreases and this decrease brings the average below the new threshold, then one may argue that the price impact post delisting may be an impact of this decrease, which almost coincides or might have influenced SEBI's decision to revise the listing criteria. On the other hand, if the above numbers are steady or increasing or do not show any differential change for the excluded stocks when compared to retained stocks, then it is difficult to make such arguments. In Figure 1, we show that the numbers remain stable during the estimation period.

Third, we perform separate price reaction tests for stocks that get excluded solely because of not meeting the revised MWPL hurdle. It is important to note that MWPL is based on proportion of outside ownership in a stock. This is unlikely to change in a span of six months unless there are some new issues or insider exits. ${ }^{23}$ Therefore, we expect MWPL to be sticky. Therefore, in order to further rule out regulatory targeting, we estimate the market model separately for stocks that were excluded solely due to a low MWPL. If such stocks also react negatively, it is further evidence that the event is indeed exogenous. It is difficult to make a case of regulatory targeting based on MWPL.

We estimate the market model only for those stocks that are excluded from the derivative segment due to not meeting the MWPL criterion. We report the CARs around the NSE announcement date in Tables 5A, 5B and 5C .

\section{Tables 5A, 5B and 5C about here}

From the tables, it is clear that stock reaction around the event is negative. The mean (median) CAR over the -5 to +5 window is $-3.7 \%$ (-4.05\%), both of which are economically

\footnotetext{
${ }^{23}$ We perform a news search and do not find any such events for stocks excluded due to MWPL.
} 
as well as statistically significant. The above result rules out the possibility of regulatory targeting. We cannot estimate the price reaction separately for stocks that get excluded for reasons other than MWPL as such stocks are very few in number.

In order to examine the long term reaction of stocks that get excluded because of MWPL, we plot the stock returns around event date in Figure 3.

\section{Figure 3 about here}

It is clear that the negative abnormal returns tend to persist even 120 days after the event date. Excluded stocks yield a cumulative abnormal negative return of nearly $11 \%$ during the 120 days after the event day. This rules out price pressure driving our results. Given that there is very little chance of regulatory targeting, this result represents a cleaner measure of impact of derivatives on stock prices.

Fourth, if the new limit for exclusion is informative, then they are likely to remain so irrespective of SEBI action. We perform placebo tests to rule out this possibility. We estimate our market model around 200 randomly selected placebo dates as event dates and calculate the average CARs around these dates. It is important to note that our treatment group or the placebo excluded sample is likely to be different for different days as we select the sample by applying SEBI's exclusion criteria on each day. For example, on April 1, 2011, which is a placebo event day, our sample includes those stocks that were a part of derivative segment as on April 1 but did not fulfill SEBI's revised criteria for continued listing as per norms declared on July 23. Here again, if reaching revised exclusion limits in itself is informative, then one can expect a negative stock price reaction even on the placebo dates. On the other hand, if our results are primarily driven by the exclusion of treatment stocks from the derivatives segment, then no price reaction is likely on the placebo dates. We estimate the market model for placebo event dates by following the procedure described above. We calculate the average AR and CAR from all placebo event dates. For the sake of brevity, we do not report the above results. On an average, we do not find any significant stock movement around the placebo dates. We find that the average of all placebo tests indicate that, in general, having either MWPL, MQSOS, or MMT within the range that led to exclusion of 51 stocks in July 2012 does not convey any price sensitive information.

Finally, the above falsification test does not address the concern that only during July 2012, due to some unobservable reasons known only to SEBI, stocks with lower levels of historical MWPL, MQSOS or MMT, under-perform the market. Therefore, the argument could be that the observed price reaction would have ensued regardless of SEBI action. In 
order to rule out such a possibility, we perform placebo tests using false limits. We create false limits for MWPL, MQSQS and MMT by keeping the event date unchanged (July 25, 2012). False limits are created at increments of INR 10,000 for all three criteria. We estimate the market model by using all possible combination of false limits. The idea here is to test if lower MWPL, MQSOS, or MMT in the previous six months indeed translates to lower returns subsequently. If lower levels of MWPL, MQSOS, or MMT lead to lower future returns, then such a phenomenon is likely to manifest even at levels other than SEBI limits. On the other hand, if the results are driven by derivative delisting, then negative returns are likely to manifest only around exclusion limits. We perform the false limit test described above. As before, we calculate the average AR and CAR. In line with our main hypothesis that the results reported in this paper are driven by derivative exclusion and not by either regulatory targeting or due to lower trading volumes, we find no significant reaction around the event days when we use false limits. Therefore, the 51 excluded stocks did not lose value due to them having lower MWPL, MQSOS, or MMT. For the sake of brevity, we do not report the above results.

\subsection{Event Study Results For Turnover}

Given the short-sale constraints in the cash market, it is difficult to argue that all traders who were trading in derivatives seamlessly move to spot markets after the exclusion of the stock from the derivative segment. We test if the trading volume in the cash market changes after exclusion from the derivatives segment. We perform the above event study using stock turnover before and after the event. We calculate abnormal volume as follows:

a. For each excluded stock, we determine the median total volume in the cash and derivatives segments between Day -70 and Day -11 relative to the announcement date.

b. Similarly, for each excluded stock, we determine the median total volume in the cash and derivatives segment or the cash segment alone (if the window includes days after September 27) over the corresponding event windows.

c. The ratio of the above measures is defined as $A b_{-} V o l$ and used as the dependent variable in the regression below.

We estimate the following regression equation:

$$
A b_{-} V o l_{\mathrm{ij}}=\alpha+\nu_{i}+\delta_{j}+\theta_{s j}+\beta_{1} * \text { Treat }+\beta_{2} * X_{i j}+\epsilon_{i j s}
$$


This is a cross sectional regression with abnormal volume of a stock $i$ during a window $j$ being the dependent variable. The sample includes only the excluded stocks. Treat is a dummy that takes the value of one for excluded stocks and zero for other stocks. $X_{i j}$ refers to firm-level control variables. We report the results of estimating equation (1) in Table 6 below.

\section{Table 6 about here}

It is important to note that actual derivative trading continued for 45 days after the event date as existing contracts traded even after notification. Keeping this in mind, we examine various event windows. Each column in the table represents a event window. Column 2 covers an interval comprising of the event day and 3 days immediately after the event. We select this window because the July contract expired on July 26 (three days from the event date of July 23). We expect a spike in volume immediately after announcement due to incremental trades aimed at closing existing open positions. We do find an insignificant change of $50.3 \%$ (column 2) in the volume from the event date to the July expiry date three days hence. We report, in columns 3 and 4, abnormal volumes for the excluded stocks for next two months separately. We find no statistically significant change in volume in the first month but a significant decrease of $37.7 \%$ in the second month. Finally, in columns 5 and 6 , we look at volume reaction after the expiration of all contracts. Here, we find that during the one-month period following the Day +44 , volumes in the spot market falls by a whopping $151.3 \%$. In other words, volumes in the cash market falls by more than a half post derivative exclusion.

It is possible to argue that some of the fall is merely a reversal of the $33.8 \%$ increase (reported in column 2) seen immediately after the announcement by SEBI. In order to asses the overall impact of derivative exclusion on trading volume in the spot market, we report the abnormal volumes for the excluded stocks when compared to retained stocks for a period of 120 days from the date of exclusion. Here, again we find that volumes decline by $28.3 \%$ for the excluded stocks when compared to retained stocks. The number is comparable to the estimate made by Berkman et al. (1998). Above results show that derivatives indeed improve liquidity in the spot market and hence add value to a stock.

\subsection{The Channel}

We then move on to examine the channels through which derivatives influence stock valuations. Specifically, we examine if derivatives 
a. enhance price efficiency of stock prices by facilitating informed trading,

b. improve liquidity of stocks, and

c. alter the volatility of stock returns.

\subsubsection{Price Efficiency - Speed of Information Assimilation}

Prior literature has examined the impact of derivatives on the price efficiency of a stock and found mixed results. A number of approaches and methods have been adopted in this regard. While some studies have developed elaborate theories (Easley et al. (1998)) regarding the price efficiency impact of derivatives, others have used clever empirical designs such as examining lead-lag relationships (Muravyev et al. (2013)), comparing the association between stock market signals and capital expenditure for stocks with high and low derivative trading volume (Roll et al. (2010)), testing the reaction of derivative and spot markets to special events such as mergers (Cao (1999)), differentiating between spot market order flow driven by derivatives and others $(\mathrm{Hu}(2014))$, etc. Although the above mentioned studies use cleverly-crafted instruments and perform a battery of robustness tests to rule out alternative explanations, lack of a truly exogenous shock to derivative trading in a stock makes them vulnerable to alternative endogenous explanations. Moreover, a clear contradiction in results in prior studies further increases the need for a study that analyzes the impact of derivatives on price efficiency in the form of an exogenous shock to derivative trading.

To test price efficiency, we use the methods developed by Hou and Moskowitz (2005) and used in Saffi and Sigurdsson (2011). The first of the two measures, called D1, is based on the idea that increased price efficiency is likely to lead to faster incorporation of marketwide news into stock prices. The above hypothesis is formally tested using the difference in the explanatory power of contemporaneous and lagged market returns in explaining current stock returns. Formally, we estimate the following regression equation to calculate $D 1$ :

$$
Y_{\mathrm{ij}}=\alpha+\nu_{i}+\beta_{1} * \text { Market }+\beta_{2} * \operatorname{Lag} 1+\beta_{3} * \operatorname{Lag} 2+\beta_{4} * \operatorname{Lag} 3+\beta_{5} * \operatorname{Lag} 4+\epsilon_{i j s}
$$

Following Hou and Moskowitz (2005), we regress the current week stock returns, which is the dependent variable in the above equation, on the market as well its four lags. We first calculate the $R^{2}$ of the above equation. Next, we re-estimate the above equation by constraining the co-efficient of the lagged values to zero and determine the $R^{2}$ of the constrained regression. One minus the ratio of $R^{2}$ from the constrained regression to that of the unconstrained regression is the first measure, D1, of price efficiency for a stock. The 
second measure, called $D 2$, is also derived from the above regression equation. Here again, following Hou and Moskowitz (2005), we calculate the ratio of the sum of co-efficients on the lagged market returns to that of the sum of all the coefficients. While the first measure, D1, focuses on the relative explanatory power of current and lagged market returns, the second one, $D 2$, focuses on the difference in economic magnitude of the influence of current and lagged market returns.

If derivatives indeed contribute positively to price efficiency, then price efficiency is likely to decrease after derivative delisting. In other words, both our measures of price efficiency should increase after derivative delisting.

Using $D 1$ and $D 2$ as measures of price efficiency, we conduct the following tests:

a. We first make a univariate comparison in a difference-in-difference sense using excluded stocks as our treatment group and all other stocks that continue in the derivative segment as our control group. Our measure of interest can be represented as follows:

$$
\begin{aligned}
\beta_{1}= & \left.\left(\bar{Y}_{\text {Treatment firms }}-\bar{Y}_{\text {Control Firms }}\right)\right|_{\text {After Derivative Exclusion }} \\
& -\left.\left(\bar{Y}_{\text {Treatment firms }}-\bar{Y}_{\text {Control firms }}\right)\right|_{\text {Before Derivative Exclusion }}
\end{aligned}
$$

b. We perform a difference-in-difference test using excluded stocks as our treatment group and all other stocks that continue in the derivative segment as our control group and test for change in price efficiency. Following (Das et al. (2014)), we call this a pooled-controlled sample. We estimate the following regression equation:

$$
Y_{\mathrm{ij}}=\alpha+\nu_{i}+\delta_{j}+\theta_{s j}+\beta_{1} * \text { Post } * \text { Treat }+\beta_{2} * \text { Post }+\beta_{3} * \text { Treat }+\beta_{4} * X_{i j}+\epsilon_{i j s}
$$

Each observation represents weekly stock returns. We cover a period from two years before to two years after the exclusion. We do not consider the period between SEBI announcement (July 23) and actual exclusion (September 27). Treat is a dummy variable that takes the value of one for excluded stocks and zero for other stocks. Post is a dummy variable that takes a value of one for the post-exclusion period and zero otherwise.

c. We perform the same test as outlined above using a matched control group. We create the matched sample following the procedure outlined in (Das et al. (2014)).

\section{Table 7A and 7B about here}


The results are reported in Tables 7A and 7B. Univariate results presented in Table 7A clearly show a significant decline in price efficiency for the treatment stocks in the post period in a difference-in-difference sense. In multivariate tests presented in 7B, we report the results for the difference-in-difference test and hence our focus is on the interaction between Post and Treat. In columns 2 and 4,D1 is the dependent variable, whereas in columns 3 and 5, D2 is the dependent variable. We use the pooled control sample in columns 2 and 3 and matched control sample in columns 4 and 5 . The explanatory power of the lagged market returns, as reflected in change in $D 1$, increases by between $7.3 \%$ to $9.6 \%$ in a difference-indifference sense. Similarly, the economic magnitude of price efficiency, as measured by D2, changes by between $5.2 \%$ to $7.1 \%$.

We do not include either time or stock fixed effects due to the exogenous nature of the event and the difference-in-difference framework used. However, in untabulated results, we estimate the above difference-in-difference regression equation using both time and stock fixed effects. Inclusion of these fixed effects do not change our results materially.

\subsubsection{Price Efficiency - Number Of Analysts Following}

Following (Damodaran and Lim (1991)), we also test if there is any change in the number of analysts following excluded stocks in the post-delisting period when compared to predelisting period. It has been recognized in the literature that analysts (Asquith et al. (2005)) contribute towards both production of new information as well as interpretation of existing information. It has also been hypothesized that informed investors prefer derivatives for various reasons (Chakravarty et al. (2004)). Given the above, we test if delisting results in reduced interest for the stock among analysts. Here again, we estimate a difference-indifference regression similar to equation (4) above. The dependent variable is the number of analysts covering a stock $i$ during a quarter $j$. All other terms remain same as in equation (4).

A negative and significant value for the difference-in-difference term would indicate that the analyst interest in the excluded stocks reduces post delisting. Such a result strengthens our view that derivatives lead to increased informed investor participation and hence their exclusion results in loss in informational efficiency. On the other hand, if derivatives have no such impact as (Vijh (1990)) shows, then we expect the difference-in-difference coefficient to be insignificant.

If a significant number of informed investors use only derivatives to exploiting their

private information, then derivative exclusion is likely to see exit of such investors from 
excluded stocks. Consequently, analyst coverage on excluded stocks is likely to decrease. We test the above phenomenon by estimating regression equation (4) with number of analysts following a stock in a quarter as the dependent variable. The results of the above regression are reported in Table 8.

\section{Table 8 about here}

Each observation is at a firm-quarter level. Our focus here is on the difference-indifference term, which represents the change in difference between analyst coverage between excluded and continuing firms in the post-exclusion period when compared to the pre-exclusion period.

We find that the number of analysts covering the treatment firms drops significantly

post exclusion. We find that on average nearly four (column 1) analysts stop covering the excluded firms because of derivative exclusion. The number drops to nearly 3 (columns 2), when we include other firm level controls. Given the above difference-in-difference result, we believe that a significant reduction in analyst coverage could have contributed to the reduced information production, which in turn could have influenced valuation of the affected stocks. We do not include either time or stock fixed effects due to the exogenous nature of the event and the difference-in-difference framework used. However, in untabulated results, we estimate the above difference-in-difference regression equation using both time and stock fixed effects. Inclusion of the above fixed effects do not change our results materially.

\subsubsection{Additional Measures of liquidity}

We recognize that trading volumes alone fails to capture the complete impact of derivatives on liquidity. Therefore, following (Das et al. (2014)), we use a battery of liquidity measures to test the impact of derivatives on stock liquidity. In total, we use twelve different liquidity measures starting from total number of trades to Amihud measure of liquidity.

We start with univariate comparisons between the excluded stocks and all other continuing stocks using a difference-in-difference framework. Our univariate comparisons can be represented using (3). The results for univariate comparisons are reported in Panels A to $\mathrm{L}$ of table $9 \mathrm{~A}$. The dependent variables, sequentially, are as follows: average daily trade (Panel A), average trade size (Panel B), Amihid illiquidity measure for cash market (Panel C), Amihid illiquidity measure for cash market plus derivative segments (Panel D), average turnover in cash market and derivative segments (Panels E and F), Roll impact measure (Panel G), total number of trades in a quarter (Panel $\mathrm{H})$, total turnover in cash market and 
total turnover in cash and derivative segments (Panels I and J), volume in cash markets and combined volume in cash and derivative segment (Panels $\mathrm{K}$ and L). Two years before SEBI notifications represents the "pre-exclusion period" and two years after actual exclusion of stocks from derivative segment represents the "post-exclusion" period.

The results clearly show a decline in liquidity. For example, in panel A of table 9A, we find that the average trade volume declines for the treatment group stocks in the postexclusion period whereas the same increases for the control group firms. We find similar results with respect to other measures of liquidity.

We then examine the impact on liquidity in a multivariate framework. We estimate regression equation (1) using each of the twelve measures as dependent variables in separate regressions. We estimate our results using both a pooled controlled sample as well as a matched controlled sample but report results only using the former. The results are reported in Table 9B.

\section{Tables 9A and 9B about here}

The independent variable of interest is the interaction between treatment and post dummies. Other control variables include measures for firm size, firm profitability and liquidity. The levels of exclusion criteria (MQSOS, MWPL, Turnover) are also used as control variables. The variable of interest is both economically as well as statistically significant in the regressions for all twelve liquidity measures. The results presented in the table clearly show liquidity worsens for stocks after their exclusion from the derivatives segment. The result remains robust to changes in the definition of liquidity.

\subsubsection{Impact on Volatility}

Although traditional asset pricing theories do not assign any weight to idiosyncratic risks in determining expected returns, subsequent empirical research has shown that such risks do matter. Lack of sufficient diversification in investor portfolios leads to such a result (Fu (2009)). Given the above findings, it is pertinent to ask if derivatives impact volatility of stock returns and thereby impact expected returns. In order to test the impact of derivatives on volatility, we estimate regression equation (4) with various measures of volatility as dependent variables. We follow (Das et al. (2014)) in devising measures of volatility. The results are reported in Table 10.

Table 10 about here 
The data are at firm-week level. In column 1, we look at change in standard deviation in a difference-in-difference setting. As before, our main dependent variable of interest is the interaction between post period dummy and the treatment dummy. From the results presented in table, it is not possible to reject the hypothesis that the difference in standard deviation of returns between treatment and the control groups remains unchanged in postexclusion period when compared to the pre-exclusion period. We next look at absolute value of returns (in column 2), number of observations with returns lower than two standard deviation from the historical average (in column 3), number of observations with returns higher than two standard deviation from the historical average (in column 4), number of observations with returns higher than two standard deviation or lower than two standard deviations from the historical average (in column 5), standard deviation given return is below two standard deviation from historical average (in column 6), standard deviation given return is above two standard deviation from historical average (in column 7), absolute difference between a day's high and low prices averaged at quarterly level (in column 8), and skewness and kurtosis (in columns 9 and 10, respectively).

There is a marginal increase in standard deviation by about $0.4 \%$. But it is significant only at $90 \%$ level and the significance vanishes when we employ fixed effects. ${ }^{24}$ Most measures except standard deviation of negative returns are statistically insignificant indicating that volatility largely remains unaffected after exclusion of derivatives. Two measures - standard deviation of negative returns and that of positive returns - are significant at the $95 \%$ level of confidence shows a reduction in volatility of negative returns and an increase in volatility of positive returns. These could be a reaction to increased short-sale constraints.

We next look at higher order moments, namely, skewness and kurtosis. As shown in the table, both the measures show a significant increase, skewness by $20.5 \%$ and kurtosis by $33.9 \%$. Increase in skewness towards the right could be attributed to increase in short-sale constraints. Increase in kurtosis points out at the increased magnitude of extreme returns for excluded stocks in the post delisting period.

From the above results, it is reasonable to conclude that derivatives have little effect on the overall volatility of stock returns. However, they lead to increased skewness and kurtosis. Therefore, extreme returns become not only more likely but also more intense in after exclusion of derivatives.

\footnotetext{
${ }^{24}$ Please note that in our reported results, we do not include either time or stock fixed effects due to the exogenous nature of the event and the difference and difference framework used. However, in untabulated results, we estimate the above difference-in-difference regression equation using both time and stock fixed effects. Inclusion of the above fixed effects do not change our results materially.
} 


\section{Conclusion}

In this paper, we revisit the question of whether derivatives are passive securities. Most studies in this area use derivatives listing or delisting as events to study the impact of derivatives on stock characteristics. However, with Mayhew and Mihov (2004) and Danielsen et al. (2007) showing that the decision of an exchange to list derivatives could be influenced by expected trends in fundamentals, a question mark has risen over the findings of the extant literature, which has used derivative listing as an event to study the impact of derivatives. Some studies have tried to overcome the same by considering stocks with high derivative trading as the ones who are likely to have maximum impact of derivatives when compared to stock with low derivative trading. However, the decision to trade derivatives on a stock might be influenced by a number of endogenous factors. And finally and most importantly, there is no consensus regarding the possible impact of derivatives on stock characteristics. Some studies show positive impact Roll et al. (2009), Conrad (1989), while some others show negative impact (Danielsen and Sorescu (2001) and some other showing no impact (Vijh (1990)).

We contribute to the literature by examining the impact of derivatives on stock fundamentals using a exogenous event. On July 23, 2012, India's market regulator issued an order tightening the eligibility criteria for continuance in the derivative segment. These criteria were based on amount of outside ownership (MWPL) and trading volume (MQSOS) during the preceding six months. The applicable limits with respect to both criteria were raised substantially. Further a third criterion based on prior six months turnover (MMT) was introduced. Thus, the change in criteria was based on purely historical information.

Using the above natural experiment, we find that derivatives indeed add value. Derivative exclusion leads to $2.82 \%$ negative cumulative abnormal returns for the excluded stocks in the five days after exclusion. We then investigate the channels of such influence. We show that derivatives impact valuation by enhancing price efficacy as well as liquidity. Contrary to the expectations of the regulators, volatility largely remains unchanged.

We rule out regulatory targeting by performing a number of placebo tests. First, we show that there is no trend in the attributes used as benchmarks for exclusion. Especially there are no jumps for excluded stocks towards the end of the estimation period. Second, we perform several placebo tests to rule out alternative explanations. Third, we estimate our main result using only those stocks that get excluded because of a relatively sticky criteria of insider ownership. All our results taken together show that derivatives indeed add value to an underlying by improving liquidity and enhancing price efficiency. 


\section{References}

Admati, A. R. And P. Pfleiderer (1988): "A theory of intraday patterns: Volume and price variability," Review of Financial studies, 1, 3-40.

Aminud, Y. And H. Mendelson (1986): "Asset pricing and the bid-ask spread," Journal of Financial Economics, 17, 223-249.

An, B.-J., A. Ang, T. G. Bali, And N. CAkici (2014): "The joint cross section of stocks and options," Journal of Finance, 69, 2279-2337.

Asquith, P., M. B. Mikhail, And A. S. Au (2005): "Information content of equity analyst reports," Journal of Financial Economics, 75, 245-282.

Berkman, H., V. R. Eleswarapu, et Al. (1998): "Short-term traders and liquidity: a test using Bombay Stock Exchange data," Journal of Financial Economics, 47, 339-355.

Bertrand, M., E. Duflo, and S. Mullainathan (2002a): "How much should we trust differences-in-differences estimates?" Tech. rep., National Bureau of Economic Research.

Bertrand, M., P. Mehta, and S. Mullainathan (2002b): "Ferreting out tunneling: An application to Indian business groups," Quaterly Journal of Economics, 117, 121-148.

Black, F. AND M. Scholes (1973): "The pricing of options and corporate liabilities," Journal of Political Economy, 81, 637-654.

Blanco, I. And D. Wehrheim (2015): "The bright side of financial derivatives: Options trading and innovation," Working paper, Universidad Carlos III de Madrid.

Boehmer, E., J. Masumeci, And A. B. Poulsen (1991): "Event-study methodology under conditions of event-induced variance," Journal of Financial Economics, 30, 253-272.

Bose, S. (2007): "Commodity futures market in India: A study of trends in the notional multi-commodity indices," ICRA Bulletin: Money $\&$ Finance, 3, 39-56.

CAO, H. H. (1999): "The effect of derivative assets on information acquisition and price behavior in a rational expectations equilibrium," Review of Financial Studies, 12, 131-163.

Chakravarty, S., H. Gulen, and S. Mayhew (2004): "Informed trading in stock and option markets," Journal of Finance, 59, 1235-1258.

Chan, K., Y. P. Chung, And W.-M. Fong (2002): "The informational role of stock and option volume," Review of Financial Studies, 15, 1049-1075.

Conrad, J. (1989): "The price effect of option introduction," Journal of Finance, 44, 487-498.

DAmodaran, A. AND J. Lim (1991): "The effects of option listing on the underlying stocks' return processes," Journal of Banking $\&$ Finance, 15, 647-664. 
Danielsen, B. R. And S. M. Sorescu (2001): "Why do option introductions depress stock prices? A study of diminishing short sale constraints," Journal of Financial and Quantitative Analysis, 36, 451-484.

Danielsen, B. R., B. F. Van Ness, and R. S. Warr (2007): "Reassessing the impact of option introductions on market quality: A less restrictive test for event-date effects," Journal of Financial and Quantitative Analysis, 42, 1041-1062.

Das, S., M. Kalimipalli, And S. NayaK (2014): "Did CDS trading improve the market for corporate bonds?" Journal of Financial Economics, 111, 495-525.

Detemple, J. And P. Jorion (1990): "Option listing and stock returns: An empirical analysis," Journal of Banking \&3 Finance, 14, 781-801.

Diamond, D. W. and R. E. Verrecchia (1987): "Constraints on short-selling and asset price adjustment to private information," Journal of Financial Economics, 18, 277-311.

Easley, D., M. O'Hara, and P. S. SRinivas (1998): "Option volume and stock prices: Evidence on where informed traders trade," Journal of Finance, 53, 431-465.

FU, F. (2009): "Idiosyncratic risk and the cross-section of expected stock returns," Journal of Financial Economics, 91, 24-37.

Gopalan, R., V. Nanda, And A. Seru (2007): "Affiliated firms and financial support: Evidence from Indian business groups," Journal of Financial Economics, 86, 759-795.

Ho, L.-C. J. AND C.-S. LiU (1997): "A reexamination of price behavior surrounding option introduction," Quarterly Journal of Business and Economics, 36, 39-50.

Hou, K. And T. J. Moskowitz (2005): "Market frictions, price delay, and the crosssection of expected returns," Review of Financial Studies, 18, 981-1020.

Hu, J. (2014): "Does option trading convey stock price information?" Journal of Financial Economics, 111, 625-645.

Johnson, T. L. And E. C. So (2012): "The option to stock volume ratio and future returns," Journal of Financial Economics, 106, 262-286.

KARlan, D. AND J. Zinman (2010): "Expanding credit access: Using randomized supply decisions to estimate the impacts," Review of Financial studies, 23, 433-464.

Kaserer, C. And B. Moldenhauer (2008): "Insider ownership and corporate performance: Evidence from Germany," Review of Managerial Science, 2, 1-35.

Kaul, A., V. Mehrotra, And R. Morck (2000): "Demand curves for stocks do slope down: New evidence from an index weights adjustment," Journal of Finance, 55, 893-912.

Khanna, T. And K. PAlePU (2000): "Is group affiliation profitable in emerging markets? An analysis of diversified Indian business groups," Journal of Finance, 55, 867-891. 
Kolari, J. W. And S. PynnÖnen (2010): "Event study testing with cross-sectional correlation of abnormal returns," Review of Financial Studies, 23, 3996-4025.

Kumar, R., A. SARIn, AND K. Shastri (1998): "The impact of options trading on the market quality of the underlying security: An empirical analysis," Journal of Finance, 53, $717-732$.

Mayhew, S. AND V. Mihov (2004): "How do exchanges select stocks for option listing?" Journal of Finance, 59, 447-471.

Mayhew, S. And V. T. Mihov (2005): "Short sale constraints, overvaluation, and the introduction of options," Unpublished manuscript.

Muravyev, D., N. D. Pearson, And J. P. Broussard (2013): "Is there price discovery in equity options?" Journal of Financial Economics, 107, 259-283.

Naiker, V., F. Navissi, And C. Truong (2012): "Options trading and the cost of equity capital," The Accounting Review, 88, 261-295.

Ni, S. X., N. D. Pearson, and A. M. Poteshman (2005): "Stock price clustering on option expiration dates," Journal of Financial Economics, 78, 49-87.

Roll, R., E. Schwartz, and A. Subrahmanyam (2009): "Options trading activity and firm valuation," Journal of Financial Economics, 94, 345-360.

- (2010): "O/S: The relative trading activity in options and stock," Journal of Financial Economics, 96, 1-17.

Ross, S. A. (1976): "Options and efficiency," Quarterly Journal of Economics, 90, 75-89.

Saffi, P. A. And K. Sigurdsson (2011): "Price efficiency and short selling," Review of Financial Studies, 24, 821-852.

Sahoo, P. And R. Kumar (2009): "Efficiency and futures trading-price nexus in Indian commodity futures markets," Global Business Review, 10, 187-201.

VIG, V. (2013): "Access to collateral and corporate debt structure: Evidence from a natural experiment," Journal of Finance, 68, 881-928.

ViJH, A. M. (1990): "Liquidity of the CBOE equity options," Journal of Finance, 45, 1157-1179. 
TABle 1: Old and New Criteria For Continued Listing In The Derivative SEGMENT

We report the old and revised criteria for continued listing in the derivative segment. All figures are reported in millions of rupees.

\begin{tabular}{lcc}
\hline Parameter & Earlier & Revised \\
\hline MWPL & 600 & 2,000 \\
MQSOS & 0.2 & 0.5 \\
MMT & NA & 1,000 \\
\hline
\end{tabular}




\section{TABle 2: Number Of Stocks Excluded Due To Various Reasons}

We report the number of stocks that get excluded because of failure to meet one or more criteria for continued listing in the derivatives segment.

\begin{tabular}{ll}
\hline Reasons for exclusion & $\begin{array}{l}\text { Number } \\
\text { of } \\
\text { Stocks }\end{array}$ \\
\hline Excluded due to MQSOS & 5 \\
Excluded due to MWPL & 30 \\
Excluded due to MMT & 4 \\
Excluded due to MQSOS/MWPL & 2 \\
Excluded due to MQSOS/MMT & 8 \\
Excluded due to MWPL/MMT & 0 \\
Excluded due to MQSOS/MWPL/MMT & 1 \\
\hline
\end{tabular}




\section{TABle 3: Summary Statistics - Comparison Between exCluded And Retained Stocks.}

We compare excluded firms and retained firms based on parameters such as sales, market capitalization, earnings, turnover, market-wide position limit and median quarter sigma order size. We report mean, median, number of observations and standard deviation for all variables. MWPL, MQSOS and turnover are reported for the six month period immediately preceding delisting. Sales and EBIT are for financial year 2011-2012. Price to book ratio is calculated based on the last available financial statement. Reported market capitalization is as on July 21, 2012. Turnover is calculated by dividing stock volume by floating market capitalization. Volume CM (F\&O) is the volume in the cash (derivatives) segment on July 23, 2012. All figures (except for ratios) in millions of rupees. Equality of means (medians) is tested using a t-test (signed rank test). ***, **, * represents statistical significance at the $1 \%, 5 \%$ and $10 \%$ levels.

\begin{tabular}{|c|c|c|c|c|c|c|c|c|c|c|}
\hline & \multicolumn{3}{|c|}{ Excluded Firms } & \multicolumn{3}{|c|}{ Continuing Firms } & & & & \\
\hline & $\mathrm{N}$ & Mean & Median & $\mathrm{N}$ & Mean & Median & Mean Diff & SR-Stats & Median Diff & T-stats \\
\hline Total Assets & 50 & $2,853.9$ & 713.0 & 154 & $7,441.4$ & $2,860.0$ & $-4,587.5^{* * *}$ & -3.2 & $-2,147.0^{* * *}$ & -4.5 \\
\hline Sales & 50 & $64,593.8$ & $25,233.4$ & 154 & $214,745.9$ & $73,741.0$ & $-150,152.1^{* * *}$ & -3.4 & $-48,507.5^{* * *}$ & -5.0 \\
\hline Market Cap & 50 & $44,561.7$ & $21,337.3$ & 154 & 292856.2 & 117804.3 & $-248294.6 * * *$ & -6.5 & $-96,467^{* * *}$ & -7.2 \\
\hline MMT & 50 & $4,464.8$ & 3237.3 & 154 & $26,018.9$ & $8,959.5$ & $-21,554.1^{* * *}$ & -4.8 & $-5,722.2^{* * *}$ & -6.2 \\
\hline MQSOS & 50 & 1.4 & 0.8 & 154 & 3.9 & 2.3 & $-2.5 * * *$ & -5.5 & $-1.6 * * *$ & -6.3 \\
\hline Price-to-Book & 47 & 2.8 & 1.3 & 153 & 3.0 & 1.9 & -0.2 & -0.2 & -0.6 & -1.5 \\
\hline Profit-to-Sales & 50 & 0.3 & 0.2 & 154 & 0.4 & 0.3 & $-0.1^{* * *}$ & -3.0 & $-0.08 * * *$ & -2.7 \\
\hline Volume CM & 50 & 79.4 & 49.9 & 154 & 407.5 & 187.0 & $-328.1^{* * *}$ & -5.6 & $-137.08 * * *$ & -6.3 \\
\hline Volume F\&O & 50 & 269.9 & 150.1 & 154 & $1,679.3$ & 578.7 & $-1,409.4^{* * *}$ & -4.7 & $-428.6 * * *$ & -5.8 \\
\hline
\end{tabular}




\section{TABLE 4A: Market Reaction to Announcement.}

The table shows the price reaction of all excluded stocks around the SEBI notification date an event-by-event basis. We consider the SEBI notification date as the event day. Event time is measured as the number of trading days from the event date. We cover a period of 5 days before and 5 days after the event. $\mathrm{N}$ (in column 2) refers to number of excluded stocks, for which we have data. AR stands for abnormal return generated by the market model for a stock i as on day d. CAR is the cumulation of AR from day -5 to day d. Columns 2 to 6 show CAR while columns 7 to 10 show AR. Std CS test refers to t-statistics computed following the procedure in Boehmer et al. (1991). T-statistics are adjusted to take into account cross-correlation due to event-date clustering using the methodology described in Kolari and Pynnönen (2010). ***, **, * represents statistical significance at the $1 \%, 5 \%$ and $10 \%$ levels.

\begin{tabular}{|c|c|c|c|c|c|c|c|c|c|}
\hline \multicolumn{6}{|c|}{ CAR } & \multicolumn{4}{|c|}{ AR } \\
\hline Event Day & $\mathrm{N}$ & Mean & Median & Std CS test & $\mathrm{S} \quad \mathrm{R}$ test & Mean & Median & Std CS test & SR test \\
\hline-5 & 50 & $0.24 \%$ & $0.22 \%$ & 0.61 & $178.5^{*}$ & $0.24 \%$ & $0.22 \%$ & 0.46 & $178.5^{*}$ \\
\hline-4 & 50 & $-0.02 \%$ & $-0.17 \%$ & -0.04 & -51.50 & $-0.26 \%$ & $-0.55 \%$ & -0.57 & $-228.5^{* *}$ \\
\hline-3 & 50 & $0.39 \%$ & $0.58 \%$ & 0.56 & 122.50 & $0.41 \%$ & $0.16 \%$ & 0.94 & $215.5^{* *}$ \\
\hline-2 & 50 & $0.89 \%$ & $0.87 \%$ & 1.04 & $205.5^{* *}$ & $0.50 \%$ & $0.16 \%$ & 1.00 & 156.50 \\
\hline-1 & 50 & $0.85 \%$ & $0.71 \%$ & 0.75 & 138.50 & $-0.04 \%$ & $-0.19 \%$ & -0.06 & -79.50 \\
\hline 0 & 50 & $-1.24 \%$ & $-0.97 \%$ & -0.85 & $-221.5^{* *}$ & $-2.09 \%$ & $-1.96 \%$ & $-2.46^{* *}$ & $-492.5^{* * *}$ \\
\hline 1 & 50 & $-1.74 \%$ & $-1.60 \%$ & -0.90 & $-301.5^{* * *}$ & $-0.49 \%$ & $-0.35 \%$ & -0.38 & -162.50 \\
\hline 2 & 50 & $-3.99 \%$ & $-3.84 \%$ & $-1.94^{*}$ & $-482.5^{* * *}$ & $-2.25 \%$ & $-1.91 \%$ & $-2.83^{* * *}$ & $-521.5^{* * *}$ \\
\hline 3 & 50 & $-3.46 \%$ & $-3.53 \%$ & $-1.74^{*}$ & $-441.5^{* * *}$ & $0.53 \%$ & $0.53 \%$ & 0.42 & $238.5^{* *}$ \\
\hline 4 & 50 & $-3.95 \%$ & $-4.46 \%$ & $-1.84^{*}$ & $-446.5^{* * *}$ & $-0.49 \%$ & $-0.78 \%$ & -0.72 & $-229.5^{* *}$ \\
\hline 5 & 50 & $-2.82 \%$ & $-2.34 \%$ & -1.26 & $-352.5^{* * *}$ & $1.13 \%$ & $1.00 \%$ & 1.55 & $369.5^{* * *}$ \\
\hline
\end{tabular}




\section{TABLE 4B: Market ReACtion to ExCLusion.}

The table shows the price reaction of all excluded stocks around the actual exclusion of stocks from the derivative segment. The actual day of exclusion is the event day here. Event time is measured as the number of trading days from the event date. We cover a period of 5 days before and 5 days after the event. $\mathrm{N}$ (in column 2) refers to number of excluded stocks, for which we have data. AR stands for abnormal return generated by the market model for a stock i as on day d. CAR is the cumulation of AR from day -5 to day d. Columns 2 to 6 show CAR while columns 7 to 10 show AR. Std CS test refers to t-statistics computed following the procedure in Boehmer et al. (1991). T-statistics are adjusted to take into account cross-correlation due to event-date clustering using the methodology described in Kolari and Pynnönen (2010). ***, **, * represents statistical significance at the $1 \%, 5 \%$ and $10 \%$ levels.

\begin{tabular}{cccccc|cccc}
\hline \multicolumn{7}{c|}{ CAR } & \multicolumn{3}{c}{ AR } \\
\hline Event Day & $\mathrm{N}$ & Mean & Median & \multicolumn{1}{c|}{ Std CS test } & \multicolumn{1}{c}{ SR test } & \multicolumn{1}{c}{ Mean } & Median & Std CS test & SR test \\
\hline-5 & 50 & $-1.45 \%$ & $-1.19 \%$ & $-1.92^{*}$ & $-410.5^{* * *}$ & $-1.45 \%$ & $-1.19 \%$ & $-1.8^{*}$ & $-410.5^{* * *}$ \\
-4 & 50 & $-1.06 \%$ & $-0.97 \%$ & -0.84 & $-242.5^{* *}$ & $0.39 \%$ & $0.34 \%$ & 0.21 & 115.50 \\
-3 & 50 & $-1.55 \%$ & $-1.61 \%$ & -1.12 & $-316.5^{* * *}$ & $-0.49 \%$ & $-0.70 \%$ & -0.71 & $-227.5^{* *}$ \\
-2 & 50 & $-1.11 \%$ & $-1.44 \%$ & -0.77 & $-185.5^{*}$ & $0.44 \%$ & $0.26 \%$ & 0.67 & 128.50 \\
-1 & 50 & $-1.51 \%$ & $-1.75 \%$ & -0.88 & $-244.5^{* *}$ & $-0.41 \%$ & $-0.29 \%$ & -0.32 & -87.50 \\
0 & 50 & $-1.89 \%$ & $-1.78 \%$ & -0.98 & $-258.5^{* *}$ & $-0.38 \%$ & $-0.31 \%$ & -0.30 & -131.50 \\
1 & 50 & $-1.25 \%$ & $-0.68 \%$ & -0.68 & -162.50 & $0.65 \%$ & $0.58 \%$ & 1.09 & $242.5^{* *}$ \\
2 & 50 & $-0.54 \%$ & $-0.62 \%$ & -0.26 & -53.50 & $0.71 \%$ & $0.29 \%$ & 0.87 & 133.50 \\
3 & 50 & $-0.16 \%$ & $-0.53 \%$ & -0.07 & 7.50 & $0.38 \%$ & $0.06 \%$ & 0.54 & 95.50 \\
4 & 50 & $0.25 \%$ & $0.05 \%$ & 0.10 & 48.50 & $0.40 \%$ & $-0.59 \%$ & 0.27 & -113.50 \\
5 & 50 & $1.04 \%$ & $0.47 \%$ & 0.40 & 110.50 & $0.80 \%$ & $0.50 \%$ & 1.00 & $242.5^{* *}$ \\
\hline
\end{tabular}


TABle 4C: Market Reaction Combined - Announcement And Actual Exclusion.

In this table, we combine both announcement period as well as actual exclusion. We cumulate returns for 11 days around announcement and 7 days around actual exclusion. N (in column 2) refers to number of excluded stocks, for which we have data. AR stands for abnormal return generated by the market model for a stock $\mathrm{i}$ as on day d. CAR is the cumulation of AR from day -5 to day d. Columns 2 to 6 show CAR while columns 7 to 10 show AR. Std CS test refers to t-statistics computed following the procedure in Boehmer et al. (1991). T-statistics are adjusted to take into account cross-correlation due to eventdate clustering using the methodology described in Kolari and Pynnönen (2010). ***, **, * represents statistical significance at the $1 \%, 5 \%$ and $10 \%$ levels.

\begin{tabular}{cccccc|cccc}
\hline \multicolumn{7}{c|}{ CAR } & \multicolumn{3}{c}{ AR } \\
\hline Event Day & N & Mean & Median & Std CS test & \multicolumn{1}{c}{ SR test } & \multicolumn{1}{c}{ Mean } & Median & Std CS test & SR test \\
\hline-5 & 50 & $0.24 \%$ & $0.22 \%$ & 0.61 & $178.5^{*}$ & $0.24 \%$ & $0.22 \%$ & 0.46 & $178.5^{*}$ \\
-4 & 50 & $-0.02 \%$ & $-0.17 \%$ & -0.04 & -51.50 & $-0.26 \%$ & $-0.55 \%$ & -0.57 & $-228.5^{* *}$ \\
-3 & 50 & $0.39 \%$ & $0.58 \%$ & 0.56 & 122.50 & $0.41 \%$ & $0.16 \%$ & 0.94 & $215.5^{* *}$ \\
-2 & 50 & $0.89 \%$ & $0.87 \%$ & 1.04 & $205.5^{* *}$ & $0.50 \%$ & $0.16 \%$ & 1.00 & 156.50 \\
-1 & 50 & $0.85 \%$ & $0.71 \%$ & 0.75 & 138.50 & $-0.04 \%$ & $-0.19 \%$ & -0.06 & -79.50 \\
0 & 50 & $-1.24 \%$ & $-0.97 \%$ & -0.85 & $-221.5^{* *}$ & $-2.09 \%$ & $-1.96 \%$ & $-2.46^{* *}$ & $-492.5^{* * *}$ \\
1 & 50 & $-1.74 \%$ & $-1.60 \%$ & -0.90 & $-301.5^{* * *}$ & $-0.49 \%$ & $-0.35 \%$ & -0.38 & -162.50 \\
2 & 50 & $-3.99 \%$ & $-3.84 \%$ & $-1.94^{*}$ & $-482.5^{* * *}$ & $-2.25 \%$ & $-1.91 \%$ & $-2.83^{* * *}$ & $-521.5^{* * *}$ \\
3 & 50 & $-3.46 \%$ & $-3.53 \%$ & $-1.74^{*}$ & $-441.5^{* * *}$ & $0.53 \%$ & $0.53 \%$ & 0.42 & $238.5^{* *}$ \\
4 & 50 & $-3.95 \%$ & $-4.46 \%$ & $-1.84^{*}$ & $-446.5^{* * *}$ & $-0.49 \%$ & $-0.78 \%$ & -0.72 & $-229.5^{* *}$ \\
5 & 50 & $-2.82 \%$ & $-2.34 \%$ & -1.26 & $-352.5^{* * *}$ & $1.13 \%$ & $1.00 \%$ & 1.55 & $369.5^{* * *}$ \\
40 & 50 & $-4.28 \%$ & $-5.05 \%$ & $-1.87^{*}$ & $-431.5^{* * *}$ & $-1.45 \%$ & $-1.19 \%$ & $-1.8^{*}$ & $-410.5^{* * *}$ \\
41 & 50 & $-3.88 \%$ & $-3.19 \%$ & -1.58 & $-375.5^{* * *}$ & $0.39 \%$ & $0.34 \%$ & 0.21 & 115.50 \\
42 & 50 & $-4.37 \%$ & $-3.33 \%$ & $-1.75^{*}$ & $-386.5^{* * *}$ & $-0.49 \%$ & $-0.70 \%$ & -0.71 & $-227.5^{* *}$ \\
43 & 50 & $-3.93 \%$ & $-3.26 \%$ & -1.55 & $-364.5^{* * *}$ & $0.44 \%$ & $0.26 \%$ & 0.67 & 128.50 \\
44 & 50 & $-4.34 \%$ & $-4.61 \%$ & $-1.83^{*}$ & $-373.5^{* * *}$ & $-0.41 \%$ & $-0.29 \%$ & -0.32 & -87.50 \\
45 & 50 & $-4.71 \%$ & $-5.12 \%$ & $-1.91^{*}$ & $-383.5^{* * *}$ & $-0.38 \%$ & $-0.31 \%$ & -0.30 & -131.50 \\
46 & 50 & $-4.07 \%$ & $-5.02 \%$ & $-1.78^{*}$ & $-365.5^{* * *}$ & $0.65 \%$ & $0.58 \%$ & 1.09 & $242.5^{* *}$ \\
\hline
\end{tabular}




\section{TABle 5A: Market Reaction to Announcement Using Stocks Excluded Due to MWPL.}

The table shows the price reaction of stocks that were excluded solely because of their failure to fulfill minimum MWPL requirement, around the SEBI notification date an event-by-event basis. We consider the SEBI notification date as the event day. Event time is measured as the number of trading days from the event date. We cover a period of 5 days before and 5 days after the event. N (in column 2) refers to number of excluded stocks, for which we have data. AR stands for abnormal return generated by the market model for a stock i as on day d. Columns 2 to 6 show CAR while columns 7 to 10 show AR. CAR is the cumulation of AR from day -5 to day d. Std CS test refers to t-statistics computed following the procedure in Boehmer et al. (1991). T-statistics are adjusted to take into account cross-correlation due to event-date clustering using the methodology described in Kolari and Pynnönen (2010). ***,**,* represents statistical significance at the 1\%, 5\% and $10 \%$ levels.

\begin{tabular}{|c|c|c|c|c|c|c|c|c|c|}
\hline \multicolumn{6}{|c|}{ CAR } & \multicolumn{4}{|c|}{$\mathrm{AR}$} \\
\hline Event Day & $\mathrm{N}$ & Mean & Median & Std CS test & S R test & Mean & Median & Std CS test & SR test \\
\hline-5 & 30 & $0.55 \%$ & $0.66 \%$ & 1.00 & $109.5^{* *}$ & $0.55 \%$ & $0.66 \%$ & 0.97 & $109.5^{* *}$ \\
\hline-4 & 30 & $0.15 \%$ & $-0.04 \%$ & 0.24 & 1.50 & $-0.40 \%$ & $-0.66 \%$ & -0.95 & $-116.5^{* *}$ \\
\hline-3 & 30 & $0.73 \%$ & $0.85 \%$ & 0.77 & $92.5^{*}$ & $0.58 \%$ & $0.32 \%$ & 0.92 & $111.5^{* *}$ \\
\hline-2 & 30 & $1.23 \%$ & $1.37 \%$ & 0.99 & $99.5^{* *}$ & $0.50 \%$ & $-0.07 \%$ & 0.68 & 24.50 \\
\hline-1 & 30 & $1.20 \%$ & $1.05 \%$ & 0.73 & 67.50 & $-0.03 \%$ & $-0.17 \%$ & -0.05 & -33.50 \\
\hline 0 & 30 & $-1.51 \%$ & $-1.93 \%$ & -0.71 & $-88.5^{*}$ & $-2.72 \%$ & $-2.78 \%$ & $-2.41^{* *}$ & $-181.5^{* * *}$ \\
\hline 1 & 30 & $-2.62 \%$ & $-1.83 \%$ & -0.88 & $-148.5^{* * *}$ & $-1.10 \%$ & $-2.64 \%$ & -0.58 & $-100.5^{* *}$ \\
\hline 2 & 30 & $-5.72 \%$ & $-5.72 \%$ & $-1.95^{*}$ & $-202.5^{* * *}$ & $-3.10 \%$ & $-3.12 \%$ & $-3.99 * * *$ & $-227.5^{* * *}$ \\
\hline 3 & 30 & $-4.75 \%$ & $-4.74 \%$ & -1.67 & $-194.5^{* * *}$ & $0.97 \%$ & $0.67 \%$ & 1.47 & $141.5^{* * *}$ \\
\hline 4 & 30 & $-5.25 \%$ & $-6.09 \%$ & -1.68 & $-179.5^{* * *}$ & $-0.50 \%$ & $-0.87 \%$ & -0.52 & $-96.5^{* *}$ \\
\hline 5 & 30 & $-3.70 \%$ & $-4.05 \%$ & -1.08 & $-152.5^{* * *}$ & $1.56 \%$ & $1.25 \%$ & $2.03^{*}$ & $180.5^{* * *}$ \\
\hline
\end{tabular}




\section{TABle 5B: Market Reaction to Exclusion For Stocks Excluded Because of MWPL.}

The table shows the price reaction of stocks that were excluded solely because of their failure to fulfill minimum MWPL requirement, around the actual exclusion of stocks from the derivative segment. The actual day of exclusion is the event day here. Event time is measured as the number of trading days from the event date. We cover a period of 5 days before and 5 days after the event. N (in column 2) refers to number of excluded stocks, for which we have data. AR stands for abnormal return generated by the market model for a stock $\mathrm{i}$ as on day $\mathrm{d}$. CAR is the cumulation of AR from day -5 to day d. Columns 2 to 6 show CAR while columns 7 to 10 show AR. Std CS test refers to t-statistics computed following the procedure in Boehmer et al. (1991). T-statistics are adjusted to take into account cross-correlation due to event-date clustering using the methodology described in Kolari and Pynnönen (2010). ***, **, * represents statistical significance at the 1\%, 5\% and $10 \%$ levels.

\begin{tabular}{|c|c|c|c|c|c|c|c|c|c|}
\hline \multicolumn{6}{|c|}{ CAR } & \multicolumn{4}{|c|}{$\mathrm{AR}$} \\
\hline Event Day & $\mathrm{N}$ & Mean & Median & Std CS test & SR test & Mean & Median & Std CS test & SR test \\
\hline-5 & 30 & $-2.28 \%$ & $-2.18 \%$ & $-2.62^{* *}$ & $-210.5^{* * *}$ & $-2.28 \%$ & $-2.18 \%$ & $-2.65^{* *}$ & $-210.5^{* * *}$ \\
\hline-4 & 30 & $-1.07 \%$ & $-1.00 \%$ & -0.65 & $-94.5^{*}$ & $1.21 \%$ & $1.03 \%$ & 1.09 & $108.5^{* *}$ \\
\hline-3 & 30 & $-1.89 \%$ & $-2.79 \%$ & -0.94 & $-125.5^{* * *}$ & $-0.82 \%$ & $-1.24 \%$ & -0.86 & $-101.5^{* *}$ \\
\hline-2 & 30 & $-1.29 \%$ & $-2.43 \%$ & -0.63 & -73.50 & $0.60 \%$ & $0.28 \%$ & 0.67 & 57.50 \\
\hline-1 & 30 & $-2.43 \%$ & $-2.01 \%$ & -1.02 & $-133.5^{* * *}$ & $-1.13 \%$ & $-1.12 \%$ & -0.86 & $-108.5^{* *}$ \\
\hline 0 & 30 & $-3.33 \%$ & $-2.82 \%$ & -1.34 & $-156.5^{* * *}$ & $-0.91 \%$ & $-0.75 \%$ & -1.12 & $-128.5^{* * *}$ \\
\hline 1 & 30 & $-2.68 \%$ & $-2.06 \%$ & -1.10 & $-134.5^{* * *}$ & $0.65 \%$ & $0.60 \%$ & 1.04 & $105.5^{* *}$ \\
\hline 2 & 30 & $-1.92 \%$ & $-1.52 \%$ & -0.73 & $-83.5^{*}$ & $0.76 \%$ & $0.35 \%$ & 0.93 & $87.5^{*}$ \\
\hline 3 & 30 & $-1.58 \%$ & $-1.87 \%$ & -0.51 & -53.50 & $0.34 \%$ & $0.06 \%$ & 0.33 & 39.50 \\
\hline 4 & 30 & $-0.59 \%$ & $-0.97 \%$ & -0.16 & -7.50 & $0.99 \%$ & $-0.38 \%$ & 0.58 & 0.50 \\
\hline 5 & 30 & $1.12 \%$ & $0.09 \%$ & 0.30 & 39.50 & $1.71 \%$ & $1.27 \%$ & $2.05^{* *}$ & $202.5^{* * *}$ \\
\hline
\end{tabular}




\section{TABle 5C: Market Reaction Combined - Announcement And Actual Exclusion.}

In this table, we combine both announcement period as well as actual exclusion. The sample is restricted to stocks that were excluded solely because of their failure to fulfill minimum MWPL requirement. We cumulate returns for 11 days around announcement and 7 days around actual exclusion. N (in column 2) refers to number of excluded stocks, for which we have data. AR stands for abnormal return generated by the market model for a stock i as on day d. CAR is the cumulation of AR from day -5 to day d. Columns 2 to 6 show CAR while columns 7 to 10 show AR. Std CS test refers to t-statistics computed following the procedure in Boehmer et al. (1991). T-statistics are adjusted to take into account cross-correlation due to event-date clustering using the methodology described in Kolari and Pynnönen (2010). ***, **, $*$ represents statistical significance at the $1 \%, 5 \%$ and $10 \%$ levels.

\begin{tabular}{|c|c|c|c|c|c|c|c|c|c|}
\hline \multicolumn{6}{|c|}{ CAR } & \multicolumn{4}{|c|}{$\mathrm{AR}$} \\
\hline Event Day & $\mathrm{N}$ & Mean & Median & Std CS test & SR test & Mean & Median & Std CS test & SR test \\
\hline-5 & 30 & $0.55 \%$ & $0.66 \%$ & 1.00 & $109.5^{* *}$ & $0.55 \%$ & $0.66 \%$ & 0.97 & $109.5^{* *}$ \\
\hline-4 & 30 & $0.15 \%$ & $-0.04 \%$ & 0.24 & 1.50 & $-0.40 \%$ & $-0.66 \%$ & -0.95 & $-116.5^{* *}$ \\
\hline-3 & 30 & $0.73 \%$ & $0.85 \%$ & 0.77 & $92.5^{*}$ & $0.58 \%$ & $0.32 \%$ & 0.92 & $111.5^{* *}$ \\
\hline-2 & 30 & $1.23 \%$ & $1.37 \%$ & 0.99 & $99.5^{* *}$ & $0.50 \%$ & $-0.07 \%$ & 0.68 & 24.50 \\
\hline-1 & 30 & $1.20 \%$ & $1.05 \%$ & 0.73 & 67.50 & $-0.03 \%$ & $-0.17 \%$ & -0.05 & -33.50 \\
\hline 0 & 30 & $-1.51 \%$ & $-1.93 \%$ & -0.71 & $-88.5^{*}$ & $-2.72 \%$ & $-2.78 \%$ & $-2.41^{* *}$ & $-181.5^{* * *}$ \\
\hline 1 & 30 & $-2.62 \%$ & $-1.83 \%$ & -0.88 & $-148.5^{* * *}$ & $-1.10 \%$ & $-2.64 \%$ & -0.58 & $-100.5^{* *}$ \\
\hline 2 & 30 & $-5.72 \%$ & $-5.72 \%$ & $-1.95^{*}$ & $-202.5^{* * *}$ & $-3.10 \%$ & $-3.12 \%$ & $-3.99 * * *$ & $-227.5^{* * *}$ \\
\hline 3 & 30 & $-4.75 \%$ & $-4.74 \%$ & -1.67 & $-194.5^{* * *}$ & $0.97 \%$ & $0.67 \%$ & 1.47 & $141.5^{* * *}$ \\
\hline 4 & 30 & $-5.25 \%$ & $-6.09 \%$ & -1.68 & $-179.5^{* * *}$ & $-0.50 \%$ & $-0.87 \%$ & -0.52 & $-96.5^{* *}$ \\
\hline 5 & 30 & $-3.70 \%$ & $-4.05 \%$ & -1.08 & $-152.5^{* * *}$ & $1.56 \%$ & $1.25 \%$ & $2.03^{*}$ & $180.5^{* * *}$ \\
\hline 40 & 30 & $-5.97 \%$ & $-6.70 \%$ & $-1.84^{*}$ & $-185.5^{* * *}$ & $-2.28 \%$ & $-2.18 \%$ & $-2.65^{* *}$ & $-210.5^{* * *}$ \\
\hline 41 & 30 & $-4.76 \%$ & $-5.00 \%$ & -1.38 & $-162.5^{* * *}$ & $1.21 \%$ & $1.03 \%$ & 1.09 & $108.5^{* *}$ \\
\hline 42 & 30 & $-5.58 \%$ & $-5.79 \%$ & -1.57 & $-163.5^{* * *}$ & $-0.82 \%$ & $-1.24 \%$ & -0.86 & $-101.5^{* *}$ \\
\hline 43 & 30 & $-4.99 \%$ & $-4.73 \%$ & -1.41 & $-160.5^{* * *}$ & $0.60 \%$ & $0.28 \%$ & 0.67 & 57.50 \\
\hline 44 & 30 & $-6.12 \%$ & $-5.15 \%$ & $-2.01^{*}$ & $-173.5^{* * *}$ & $-1.13 \%$ & $-1.12 \%$ & -0.86 & $-108.5^{* *}$ \\
\hline 45 & 30 & $-7.03 \%$ & $-6.46 \%$ & $-2.36 * *$ & $-190.5^{* * *}$ & $-0.91 \%$ & $-0.75 \%$ & -1.12 & $-128.5^{* * *}$ \\
\hline 46 & 30 & $-6.38 \%$ & $-6.31 \%$ & $-2.35^{* *}$ & $-196.5^{* * *}$ & $0.65 \%$ & $0.60 \%$ & 1.04 & $105.5^{* *}$ \\
\hline
\end{tabular}




\section{TABle 6: Market Reaction - Event Study Based on Volume}

This is a cross sectional regression with abnormal volume of a stock $\mathrm{i}$ during a window $\mathrm{j}$ being the dependent variable. The total sample includes retained as well as excluded stocks. Treat is a dummy that takes the value of one for excluded stocks and zero for other stocks. We include firm level control variables similar to the ones used before. We report different intervals (specified in top row) of time around the event day in different columns.

\begin{tabular}{rcccccr}
\hline Window & $(-10,-1)$ & $(0,+1)$ & $(+2,+25)$ & $(+26,+44)$ & $(+45,+62)$ & $(+45,+120)$ \\
\hline Treatment & -0.009 & 0.503 & -0.123 & $-0.377^{* *}$ & $-1.513^{* * *}$ & $-1.373^{* * *}$ \\
& $(0.108)$ & $(0.524)$ & $(0.104)$ & $(0.150)$ & $(0.252)$ & $(0.187)$ \\
Observations & 200 & 200 & 200 & 199 & 199 & 198 \\
R-squared & 0.004 & 0.166 & 0.020 & 0.053 & 0.159 & 0.162 \\
Adj R-squared & -0.017 & 0.148 & 0.000 & 0.034 & 0.142 & 0.144 \\
\hline
\end{tabular}




\section{TABLE 7A: Price EFficiency -Univariate Comparisons}

The table shows the impact of derivatives on price efficiency in a univariate framework. An observation represents a firm quarter. The sample consists of all stocks that were listed in the derivative segment before exclusion. Stocks that get excluded form the treatment group and those that continue to be listed in the derivative segment form the control group. The dependent variables, D1 and D2 are measures of price delay devised by (Hou and Moskowitz (2005)). Two years before SEBI notifications represents the pre period and two years after actual exclusion of stocks from derivative segment represents the post period.

Standard errors are reported in parentheses. $* * *, * *, *$ represents statistical significance at $1 \%, 5 \%$ and $10 \%$ levels.

\begin{tabular}{|l|c|c|c|c|c|c|}
\hline & \multicolumn{3}{|c|}{ D1 } & \multicolumn{2}{c|}{ D2 } \\
\hline \multicolumn{1}{|c|}{ Period } & Treatment & Control & Diff $(\mathrm{T}-\mathrm{C})$ & Treatment & Control & Diff $(\mathrm{T}-\mathrm{C})$ \\
\hline Pre & 0.360 & 0.381 & $-0.021(0.887)$ & 0.566 & 0.58 & $-0.013(0.878)$ \\
\hline Post & 0.503 & 0.428 & $0.075^{* * *}(-2.97)$ & 0.665 & 0.612 & $0.053^{* * *}(-3.77)$ \\
\hline Diff (Post-Pre) & $0.144^{* * *}(6.373)$ & $0.047^{* * *}(3.775)$ & 0.096 & $0.099^{* * *}(7.801)$ & $0.032^{* * *}(4.387)$ & 0.066 \\
\hline
\end{tabular}




\section{TABLE 7B: PRICE EFfICIENCY}

The table shows the impact of derivatives on price efficiency. An observation represents a firm quarter. In columns 2 and 3, the sample consists of all stocks that were listed in the derivative segment before exclusion. Stocks that get excluded form the treatment group and those that continue to be listed in the derivative segment form the control group. In columns 4 and 5, the control group consists of matched sample of firms. The dependent variables, D1 and D2 are measures of price delay devised by (Hou and Moskowitz (2005)). Two years before SEBI notifications represents the pre period and two years after actual exclusion of stocks from derivative segment represents the post period. The independent variable of interest is the interaction between treatment and post dummies. Other control variables include measures for firm size, firm profitability and liquidity. The levels of exclusion criteria (MQSOS, MWPL, Turnover) are also used as control variables. Errors are clustered at firm level and adjusted for heteroscedasticity. Standard errors are reported in parentheses. ***, $* *, *$ represents statistical significance at $1 \%, 5 \%$ and $10 \%$ levels.

\begin{tabular}{lcccc}
\hline VARIABLES & D1 & D2 & D1 & D2 \\
\hline Treatment & & & & \\
& 0.008 & 0.003 & $-0.056^{*}$ & $-0.038^{*}$ \\
Post event & $(0.022)$ & $(0.014)$ & $(0.033)$ & $(0.020)$ \\
& $0.052^{* * *}$ & $0.037^{* * *}$ & 0.033 & 0.021 \\
Interaction & $(0.012)$ & $(0.007)$ & $(0.031)$ & $(0.016)$ \\
(Treat*Post) & $0.073^{* * *}$ & $0.052^{* * *}$ & $0.096^{* *}$ & $0.071^{* * *}$ \\
& $(0.026)$ & $(0.015)$ & $(0.040)$ & $(0.021)$ \\
Observations & & & & \\
Adj R-squared & 3,146 & 3,146 & 1,011 & 1,011 \\
Number of Companies & 0.0384 & 0.0406 & 0.0728 & 0.0811 \\
Control Vars & 204 & 204 & 68 & 68 \\
Firm FE & Yes & Yes & Yes & Yes \\
Time FE & No & No & No & No \\
\hline
\end{tabular}




\section{TABle 8: Analyst Following Before And After Exclusion}

The table shows the impact of derivative exclusion on analyst coverage of a stock. The total sample includes firms that are excluded from the derivative segment and those that continue to have derivatives traded on them even after the SEBI order. The dependent variable is the number of analysts following an firm $i$ as at end of quarter $j$ when compared to the same as at the end of quarter $\mathrm{j}-1$. The independent variable after is a dummy variable that takes the value of 1 if quarter $i$ lies in the post delisting period and zero otherwise. Treat is a dummy that takes the value of 1 if the stock i under consideration is an excluded stock and zero otherwise. The main independent variable of interest is the interaction between After and Treat dummies. We also include firm level controls for size(market cap), insider holding(MWPL) and liquidity (MQSOS). In column 1 we do not include any control variable. In column 2 we include other control variables. T-statistics are reported in parenthesis. ${ }^{* * *}$, **, * represents statistical significance at the $1 \%, 5 \%$ and $10 \%$ levels.

\begin{tabular}{lcc}
\hline VARIABLES & Analyst Reco. & Analyst Reco. \\
\hline & & \\
Treatment & $-18.566^{* * *}$ & $-10.510^{* * *}$ \\
& $(1.875)$ & $(1.911)$ \\
Post event & $3.054^{* * *}$ & $3.320^{* * *}$ \\
& $(0.564)$ & $(0.458)$ \\
Interaction & $-4.132^{* * *}$ & $-2.675^{* * *}$ \\
(Treat*Post) & $(1.157)$ & $(1.023)$ \\
& & \\
Observations & 3,160 & 3,076 \\
Number of companies & 0.0808 & 0.192 \\
Adj R-squared & 204 & 203 \\
Control Vars & No & Yes \\
Firm FE & No & No \\
Time FE & No & No \\
\hline
\end{tabular}




\section{TABLE 9A: Impact On Liquidity - Summary Statistics}

The table shows the impact of derivatives Liquidity. The sample consists of all stocks that were listed in the derivative segment before exclusion. Stocks that get excluded form the treatment group and those that continue to be listed in the derivative segment form the control group. Each observation represents a firm-quarter. We use the liquidity measures devised by Das et al. (2014). The dependent variables, sequentially, are as follows: average daily trade (Panel A), average trade size (Panel:B), Amihid illiquidity measure for cash market, Amihid illiquidity measure for cash market and derivative segments (Panels $\mathrm{C}$ and D), average turnover in cash market derivative segments (Panels E and F), Roll impact measure (Panel G), total number of trades in a quarter(Panel H), total turnover in cash market and total turnover in cash and derivative segment(Panel I and J), Volume in cash markets and combined volume in cash and derivative segment (Panels K and L). Two years before SEBI notifications represents the pre period and two years after actual exclusion of stocks from derivative segment represents the post period. The independent variable of interest is the interaction between treatment and post dummies. Other control variables include measures for firm size, firm profitability and liquidity. The levels of exclusion criteria (MQSOS, MWPL, Turnover) are also used as control variables. Errors are clustered at firm level and adjusted for heteroscedasticity. Standard errors are reported in parentheses. ***, **, * represents statistical significance at $1 \%, 5 \%$ and $10 \%$ levels.

\begin{tabular}{|r|c|c|c|}
\hline \multicolumn{4}{|c|}{ Panel A: Avg Daily Trade } \\
\hline & Treatment & Control & Diff (T-C) \\
\hline Pre & 11381.01 & 23318.50 & $-11937.497^{* * *}(4.105)$ \\
\hline Post & 6724.93 & 28241.91 & $-21516.987^{* * *}(6.947)$ \\
\hline Diff (Post-Pre) & $-4656.076^{* * *}(-4.768)$ & $4923.414^{* * *}(5.411)$ & -9579.49 \\
\hline
\end{tabular}

\begin{tabular}{|r|c|c|c|}
\hline \multicolumn{4}{|c|}{ Panel B: Avg Trade Size } \\
\hline & Treatment & Control & Diff (T-C) \\
\hline Pre & 15370.66 & 21081.10 & $-5710.44^{* * *}(3.552)$ \\
\hline Post & 12549.78 & 19966.04 & $-7416.26^{* * *}(4.881)$ \\
\hline Diff (Post-Pre) & $-2820.88^{* * *}(-4.919)$ & $-1115.06^{* * *}(-2.613)$ & -1705.82 \\
\hline
\end{tabular}

\begin{tabular}{|r|c|c|c|}
\hline \multicolumn{4}{|c|}{ Panel C: Amihud Illiquidity Cash Market } \\
\hline & Treatment & Control & Diff (T-C) \\
\hline Pre & 24192.90 & 91842.74 & $-67649.84(0.465)$ \\
\hline Post & 91892.10 & 875273.79 & $-783381.69(0.516)$ \\
\hline Diff (Post-Pre) & $67699.20^{* * *}(4.231)$ & $783431.05(1.003)$ & -715732 \\
\hline
\end{tabular}




\begin{tabular}{|r|c|c|c|}
\hline \multicolumn{4}{|c|}{ Panel D: Amihud Illiquidity Cash and Derivatives } \\
\hline & Treatment & Control & Diff (T-C) \\
\hline Pre & 9471.26 & 3655.38 & $5815.885^{* * *}(-7.12)$ \\
\hline Post & 91891.34 & 35407.93 & $56483.416(-1.123)$ \\
\hline Diff (Post-Pre) & $82420.08^{* * *}(5.013)$ & $31752.55(1.131)$ & 50667.53 \\
\hline
\end{tabular}

\begin{tabular}{|r|c|c|c|}
\hline \multicolumn{4}{|c|}{ Panel E:Avg Turnover $(\mathrm{CM}))$} \\
\hline & Treatment & Control & Diff $(\mathrm{T}-\mathrm{C})$ \\
\hline Pre & 0.541 & 0.297 & $0.244^{* * *}(-3.526)$ \\
\hline Post & 0.265 & 0.354 & $-0.089(1.303)$ \\
\hline Diff (Post-Pre) & $-0.276^{* * *}(-4.171)$ & $0.057^{* *}(2.319)$ & -0.333 \\
\hline
\end{tabular}

\begin{tabular}{|r|c|c|c|}
\hline \multicolumn{4}{|c|}{ Panel F: Avg Turnover Spot and Futues ) } \\
\hline & Treatment & Control & Diff (T-C) \\
\hline Pre & 1.363 & 1.138 & $0.225(-0.585)$ \\
\hline Post & 0.265 & 1.527 & $-1.262^{* * *}(3.026)$ \\
\hline Diff (Post-Pre) & $-1.098^{* * *}(-5.602)$ & $0.389^{* * *}(3.487)$ & $\mathbf{- 1 . 4 8 7}$ \\
\hline
\end{tabular}

\begin{tabular}{|r|c|c|c|}
\hline \multicolumn{4}{|c|}{ Panel G: Roll Impact Factor } \\
\hline & Treatment & Control & Diff (T-C) \\
\hline Pre & 11444.92 & 1952.32 & $9492.60^{* *}(-2.494)$ \\
\hline Post & 13730.60 & 2947.45 & $10783.15^{* * *}(-4.304)$ \\
\hline Diff (Post-Pre) & $2285.685(0.316)$ & $995.132(1.166)$ & 1290.55 \\
\hline
\end{tabular}

\begin{tabular}{|r|c|c|c|}
\hline \multicolumn{4}{|c|}{ Panel H: Total Trades } \\
\hline & Treatment & Control & Diff (T-C) \\
\hline Pre & 713694.1 & 1462290 & $-748595.437^{* * *}(4.109)$ \\
\hline Post & 416059 & 1749781 & $-1333722.228^{* * *}(6.94)$ \\
\hline Diff (Post-Pre) & $-297635.165^{* * *}(-4.860)$ & $287491.625^{* * *}(5.068)$ & -585127 \\
\hline
\end{tabular}

\begin{tabular}{|r|c|c|c|}
\hline \multicolumn{4}{|c|}{ Panel I: Turnover Spot Markets } \\
\hline & Treatment & Control & Diff $(\mathrm{T}-\mathrm{C})$ \\
\hline Pre & 45.947 & 22.681 & $23.266^{* * *}(-4.255)$ \\
\hline Post & 24.857 & 26.667 & $-1.809(0.343)$ \\
\hline Diff (Post-Pre) & $-21.09^{* * *}(-3.780)$ & $3.986^{* *}(2.034)$ & -25.076 \\
\hline
\end{tabular}

\begin{tabular}{|r|c|c|c|}
\hline \multicolumn{4}{|c|}{ Panel J: Turnover Spot and Futures Markets } \\
\hline & Treatment & Control & Diff $(\mathrm{T}-\mathrm{C})$ \\
\hline Pre & 112.439 & 90.825 & $21.613(-0.606)$ \\
\hline Post & 24.905 & 114.474 & $-89.568^{* * *}(2.901)$ \\
\hline Diff (Post-Pre) & $-87.533^{* * *}(-5.916)$ & $23.648^{* * *}(2.668)$ & -111.182 \\
\hline
\end{tabular}




\begin{tabular}{|r|c|c|c|}
\hline \multicolumn{4}{|c|}{ Panel K: Total Volume Spot } \\
\hline & Treatment & Control & Diff (T-C) \\
\hline Pre & 10925.33 & 37489.51 & $-26564.17^{* * *}(3.644)$ \\
\hline Post & 5571.37 & 42165.40 & $-36594.04^{* * *}(5.372)$ \\
\hline Diff (Post-Pre) & $-5353.97^{* * *}(-4.369)$ & $4675.90^{* *}(2.481)$ & -10029.86 \\
\hline
\end{tabular}

\begin{tabular}{|r|c|c|c|}
\hline \multicolumn{4}{|c|}{ Panel L: Total Volume Spot And Derivative } \\
\hline & Treatment & Control & Diff (T-C) \\
\hline Pre & 26970.20 & 119996.86 & $-93026.67^{* * *}(3.528)$ \\
\hline Post & 5621.49 & 176213.14 & $-170591.648^{* * *}(4.998)$ \\
\hline Diff (Post-Pre) & $-21348.711^{* * *}(-7.125)$ & $56216.271^{* * *}(5.955)$ & -77564.98 \\
\hline
\end{tabular}




\section{TABLE 9B: Impact on Liquidity - Regression Based Tests}

The table shows the impact of derivatives Liquidity. The sample consists of all stocks that were listed in the derivative segment before exclusion. Stocks that get excluded form the treatment group and those that continue to be listed in the derivative segment form the control group. Each observation represents a firm-quarter. We use the liquidity measures devised by Das et al. (2014). The dependent variables, sequentially, are as follows: total number of trades in a quarter, average daily trades, total volume in cash market, total volume in cash and derivative segments, average trade size, turnover in cash market, turnover in cash and derivative segment, average turnover in cash market, average turnover in cash and derivative segment, Amihid illiquidity measure for cash market, Amihid illiquidity measure for cash market and derivative market and Rollimpact measure. Two years before SEBI notifications represents the pre period and two years after actual exclusion of stocks from derivative segment represents the post period. The independent variable of interest is the interaction between treatment and post dummies. Other control variables include measures for firm size, firm profitability and liquidity. The levels of exclusion criteria (MQSOS, MWPL, Turnover) are also used as control variables. Errors are clustered at firm level and adjusted for heteroscedasticity. Standard errors are reported in parentheses. ***,**,* represents statistical significance at 1\%, 5\% and $10 \%$ levels.

\begin{tabular}{|c|c|c|c|c|c|c|c|c|c|c|c|c|}
\hline VARIABLES & Total Trades & Avg Daily Trade & Total Volume (CM) & Total Volume (CM, F\&O) & Avg Trade Size & Turnover (CM) & Turnover (CM, F\&0) & Avg Turnover (CM) & Avg Turnover (CM, F\&O) & Amihud Illiquidity (CM) & Amihud Illiquidity (CM,F\&0) & Roll Impact \\
\hline Treatment & $\begin{array}{l}-0.081 \\
(0.128)\end{array}$ & $\begin{array}{c}-0.083 \\
(0.128)\end{array}$ & $\begin{array}{l}0.107 \\
(0.132)\end{array}$ & $\begin{array}{c}0.127 \\
(0.109)\end{array}$ & $\begin{array}{c}0.239 \text { *** } \\
(0.069)\end{array}$ & $\begin{array}{c}0.123 \\
(0.133)\end{array}$ & $\begin{array}{c}0.139 \\
(0.110)\end{array}$ & $\begin{array}{c}0.082 \\
(0.140)\end{array}$ & $\begin{array}{c}0.091 \\
(0.114)\end{array}$ & $\begin{array}{c}-0.296^{* *} \\
(0.135)\end{array}$ & $\begin{array}{c}-0.268^{* *} \\
(0.109)\end{array}$ & $\begin{array}{l}0.391^{*} \\
(0.236)\end{array}$ \\
\hline Post event & $\begin{array}{c}0.121^{* * *} \\
(0.031)\end{array}$ & $\begin{array}{c}0.137 * * * \\
(0.030)\end{array}$ & $\begin{array}{l}0.052 \\
(0.032)\end{array}$ & $\begin{array}{c}0.176^{* * *} \\
(0.045)\end{array}$ & $\begin{array}{c}-0.057 * * * \\
(0.016)\end{array}$ & $\begin{array}{l}0.047 \\
(0.032)\end{array}$ & $\begin{array}{c}0.172 * * * \\
(0.046)\end{array}$ & $\begin{array}{l}0.064^{* *} \\
(0.033)\end{array}$ & $\begin{array}{c}0.179^{* * *} \\
(0.048)\end{array}$ & $\begin{array}{c}-0.092 * * * \\
(0.030)\end{array}$ & $\begin{array}{c}-0.205 * * * \\
(0.046)\end{array}$ & $\begin{array}{c}-0.211^{* * *} \\
(0.058)\end{array}$ \\
\hline $\begin{array}{l}\text { Interaction } \\
\text { (Treat*Post) }\end{array}$ & $\begin{array}{c}-0.352^{* * * *} \\
(0.079)\end{array}$ & $\begin{array}{c}-0.355 * * * \\
(0.079)\end{array}$ & $\begin{array}{c}-0.433^{* * *} \\
(0.089)\end{array}$ & $\begin{array}{c}-1.422 * * * \\
(0.110)\end{array}$ & $\begin{array}{l}-0.063^{*} \\
(0.034)\end{array}$ & $\begin{array}{c}-0.435^{* * *} \\
(0.087)\end{array}$ & $\begin{array}{c}-1.422^{\text {*** }} \\
(0.109)\end{array}$ & $\begin{array}{c}-0.515^{* * *} \\
(0.085)\end{array}$ & $\begin{array}{c}-1.478^{* * * *} \\
(0.108)\end{array}$ & $\begin{array}{c}0.450 * * * \\
(0.076)\end{array}$ & $\begin{array}{c}1.430^{* * * *} \\
(0.103)\end{array}$ & $\begin{array}{c}1.222^{* * * *} \\
(0.148)\end{array}$ \\
\hline Observations & 3,161 & 3,161 & 3,161 & 3,161 & 3,161 & 3,161 & 3,161 & 3,161 & 3,161 & 3,161 & 3,161 & 1,380 \\
\hline Adj R-squared & 0.236 & 0.236 & 0.365 & 0.493 & 0.408 & 0.179 & 0.351 & 0.231 & 0.374 & 0.511 & 0.567 & 0.278 \\
\hline Number of Companies & 204 & 204 & 204 & 204 & 204 & 204 & 204 & 204 & 204 & 204 & 204 & 204 \\
\hline Control Vars & Yes & Yes & Yes & Yes & Yes & Yes & Yes & Yes & Yes & Yes & Yes & Yes \\
\hline Firm FE & No & No & No & No & No & No & No & No & No & No & No & No \\
\hline Time FE & No & No & No & No & No & No & No & No & No & No & No & No \\
\hline
\end{tabular}




\section{TABLE 10: IMPACT ON Volatility}

The table shows the impact of derivatives Liquidity. The sample consists of all stocks that were listed in the derivative segment before exclusion. Stocks that get excluded form the treatment group and those that continue to be listed in the derivative segment form the control group. Each observation represents a firm-quarter. We use the liquidity measures devised by Das et al. (2014). The dependent variables, sequentially, absolute value of returns (in column 2), number of observations with returns lower than two standard deviation from the historical average(in column 3), number of observations with returns higher than two standard deviation from the historical average(in column 4), number of observations with returns higher than two standard deviation or lower than two standard deviations from the historical average(in column 5), standard deviation given return is below two standard deviation from historical average(in column 6), standard deviation given return in below two standard deviation from historical average(in column 7), absolute difference between a day's high and low price averaged at quarterly level (in column 8), skewness and kurtosis (in columns 9 and 10 respectively). Two years before SEBI notifications represents the pre period and two years after actual exclusion of stocks from derivative segment represents the post period. The independent variable of interest is the interaction between treatment and post dummies. Other control variables include measures for firm size, firm profitability and liquidity. The levels of exclusion criteria (MQSOS, MWPL, Turnover) are also used as control variables. Errors are clustered at firm level and adjusted for heteroscedasticity. Standard errors are reported in parentheses. $* * *, * *, *$ represents statistical significance at $1 \%, 5 \%$ and $10 \%$ levels.

\begin{tabular}{|c|c|c|c|c|c|c|c|c|c|c|}
\hline VARIABLES & Std Dev & -Return- & Down & Up & Up or Down & Down Risk & Up Risk & High-Low & Skewness & Kurtosis \\
\hline Treatment & $\begin{array}{c}-0.004 * * \\
(0.002)\end{array}$ & $\begin{array}{c}-0.181^{* * *} \\
(0.051)\end{array}$ & $\begin{array}{c}0.008 \\
(0.005)\end{array}$ & $\begin{array}{l}-0.004 \\
(0.003)\end{array}$ & $\begin{array}{c}0.003 \\
(0.004)\end{array}$ & $\begin{array}{l}-0.000 \\
(0.000)\end{array}$ & $\begin{array}{c}0.001 \\
(0.004)\end{array}$ & $\begin{array}{c}-0.263 * * * \\
(0.095)\end{array}$ & $\begin{array}{c}0.068 \\
(0.048)\end{array}$ & $\begin{array}{c}0.055 \\
(0.105)\end{array}$ \\
\hline Post event & $\begin{array}{l}0.001 \\
(0.001)\end{array}$ & $\begin{array}{l}-0.003 \\
(0.018)\end{array}$ & $\begin{array}{l}-0.002 \\
(0.004)\end{array}$ & $\begin{array}{c}0.008 * * * \\
(0.002)\end{array}$ & $\begin{array}{l}0.006 * \\
(0.003)\end{array}$ & $\begin{array}{l}-0.000 \\
(0.000)\end{array}$ & $\begin{array}{l}0.001 * \\
(0.001)\end{array}$ & $\begin{array}{c}-0.086 * * * \\
(0.031)\end{array}$ & $\begin{array}{c}0.079^{* * *} * \\
(0.030)\end{array}$ & $\begin{array}{c}0.262^{* * *} \\
(0.068)\end{array}$ \\
\hline $\begin{array}{l}\text { Interaction } \\
\text { (Treat*Post) }\end{array}$ & $\begin{array}{l}0.004^{*} \\
(0.002)\end{array}$ & $\begin{array}{c}0.046 \\
(0.048)\end{array}$ & $\begin{array}{c}-0.013^{* *} \\
(0.005)\end{array}$ & $\begin{array}{c}0.009^{* *} \\
(0.004)\end{array}$ & $\begin{array}{l}-0.005 \\
(0.004)\end{array}$ & $\begin{array}{c}0.000 \\
(0.000)\end{array}$ & $\begin{array}{c}0.004 \\
(0.007)\end{array}$ & $\begin{array}{c}0.054 \\
(0.078)\end{array}$ & $\begin{array}{c}0.205^{* * *} * \\
(0.066)\end{array}$ & $\begin{array}{c}0.339^{* *} \\
(0.167)\end{array}$ \\
\hline Observations & 3,146 & 3,146 & 3,146 & 3,146 & 3,146 & 3,141 & 275 & 3,146 & 3,146 & 3,146 \\
\hline Adj R-squared & 0.0589 & 0.0842 & 0.0183 & 0.0269 & 0.00485 & 0.0861 & 0.00630 & 0.105 & 0.0169 & 0.0135 \\
\hline Number of Companies & 204 & 204 & 204 & 204 & 204 & 204 & 161 & 204 & 204 & 204 \\
\hline Control Vars & Yes & Yes & Yes & Yes & Yes & Yes & Yes & Yes & Yes & Yes \\
\hline Firm FE & No & No & No & No & No & No & No & No & No & No \\
\hline Time FE & No & No & No & No & No & No & No & No & No & No \\
\hline
\end{tabular}


Figure 1: TREnd In ExCLUSION CRITERIA

The three lines correspond to the three exclusion criteria described in 3. The grey lines represent the threshold limit for exclusion. The thick lines represent the average values for the stocks that get eventually excluded.

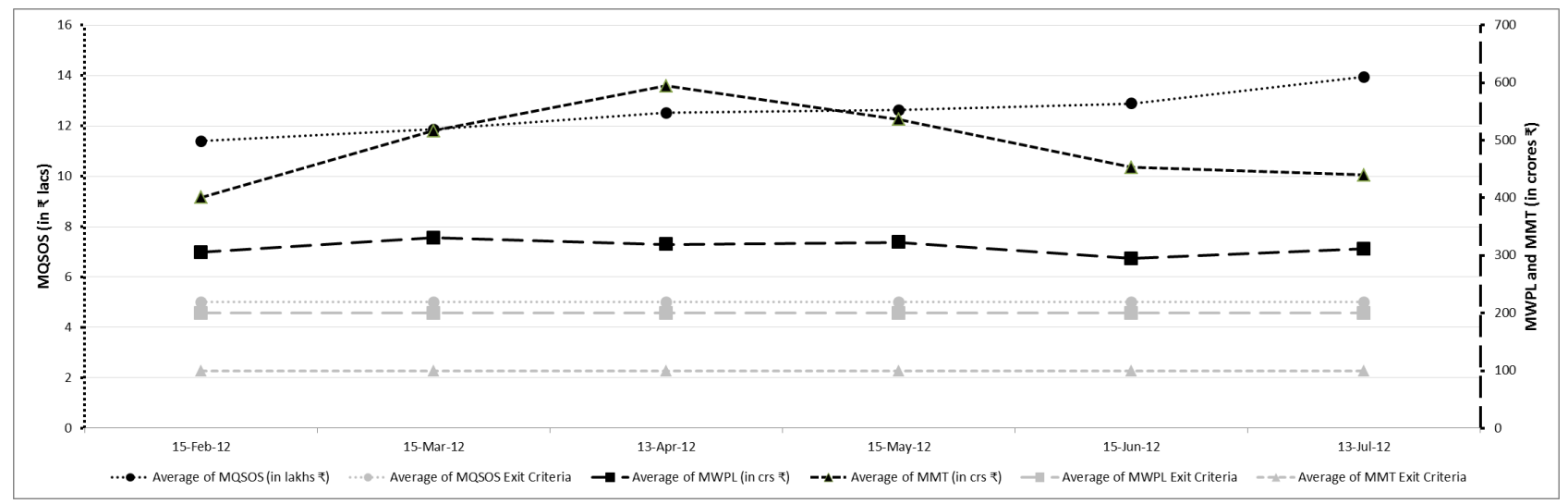


Figure 2: Market Reaction - All Excluded Stocks

This figure depicts the event study results for a period starting from 10 days before the NSE's announcement of the list companies being excluded from the derivatives segment to 120 days after the announcement. The first blue vertical line denotes the NSE announcement date (July 25) and the second vertical blue line denotes the actual exclusion day (September $27)$.

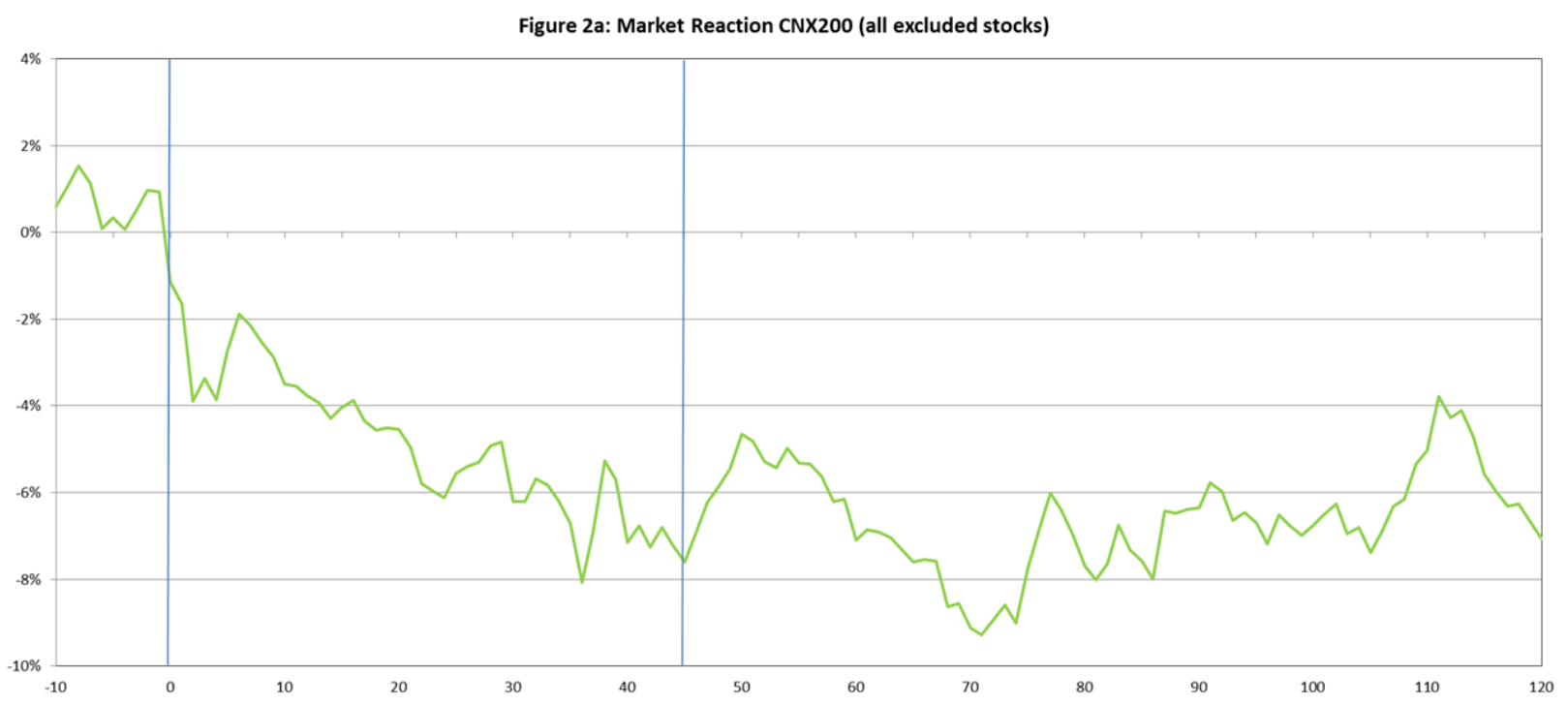


Figure 3: Market Reaction - Stocks Excluded Due to MWPL

This figure depicts the event study results for a period starting from 10 days before the NSE's announcement of the list companies being excluded from the derivatives segment . The event study is restricted to stocks that got excluded solely due to failure to comply with the MWPL requirement. The first blue vertical line denotes the NSE announcement date (July 25) and the second vertical blue line denotes the actual exclusion day (September 27).

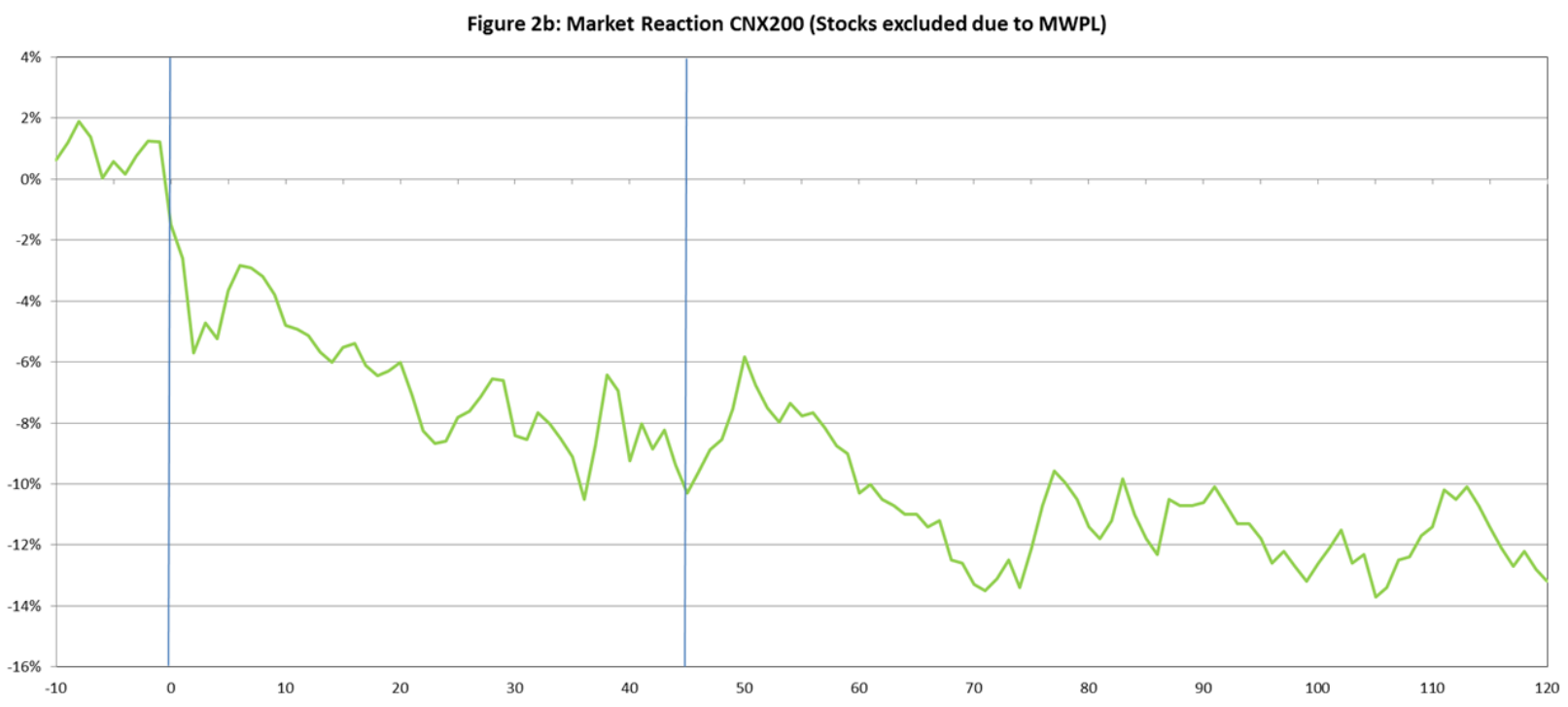

